\title{
Flora vascular da Reserva Biológica da Represa do Grama, Minas Gerais, e sua relação florística com outras florestas do sudeste brasileiro
}

\author{
Vascular flora of the Reserva Biológica da Represa do Grama, Minas Gerais, \\ and its floristic relationships with other forests from Southeastern Brazil
}

\author{
Rafaela Campostrini Forzza ${ }^{1,8}$, Daniel Salgado Pifano ${ }^{2,8}$, Ary Teixeira de Oliveira-Filho ${ }^{3}$, \\ Leonardo Dias Meireles ${ }^{4}$, Patrícia Lobo Faria ${ }^{5}$, Fátima Regina Salimena ${ }^{6}$, Claudine M. Mynssen ${ }^{1}$ \\ \& Jefferson Prado ${ }^{7}$
}

\begin{abstract}
Resumo
Este trabalho apresenta o levantamento florístico das plantas vasculares da Reserva Biológica da Represa do Grama, um remanescente de floresta estacional semidecidual do Domínio Atlântico, situado no município de Descoberto, Minas Gerais. Foram realizadas coletas quinzenais de material fértil entre agosto de 1999 e dezembro de 2004. Além do levantamento, fez-se a comparação da composição florística através de análises multivariadas de agrupamento com outras nove áreas (3 de floresta estacional e 6 de ombrófila), cujos levantamentos florísticos de angiospermas tiveram abordagem semelhante. Cada análise foi processada para o conjunto total das espécies e para oito hábitos: árvores (incluindo arvoretas), arbustos, trepadeiras (lenhosas e herbáceas), ervas terrícolas, ervas saxícolas, epífitas, hemiepífitas e parasitas. Na ReBio do Grama foram registradas 644 espécies de angiospermas, distribuídas em 370 gêneros e 100 famílias. Licófitas e samambaias estão representadas por 64 espécies, distribuídas em 37 gêneros e 16 famílias. Seis espécies de angiospermas foram descritas como novas para a ciência. Fabaceae ( $55 \mathrm{spp}$.) foi a família com maior riqueza específica, seguida de Rubiaceae (50 spp.), Melastomataceae (28 spp.), Bignoniaceae e Orchidaceae (27 spp. cada) e Myrtaceae (25 spp.). As análises multivariadas sugeriram que os gradientes longitudinais, latitudinais e altitudinais interferem de formas distintas sobre os padrões de riqueza dos diferentes hábitos. O número reduzido de espécies compartilhadas entre as áreas, associado com alta riqueza regionalizada de alguns hábitos demonstra a importância da conservação de fragmentos nas diferentes regiões geográficas da Floresta Atlântica como estratégia para maximizar a conservação da diversidade existente neste domínio fitogeográfico. Palavras-chave: composição florística, Mata Atlântica, Zona da Mata.
\end{abstract}

\begin{abstract}
The vascular plants survey of a remnant of semideciduous seasonal forest in the Atlantic Forest Biome was carried out in the ReBio do Grama, municipality of Descoberto, Minas Gerais, through forthnightly trips to collect fertile specimens between August 1999 and December 2004. The angiosperms included 644 species distributed in 370 genera and 100 families, including 6 species new to science, while the lycophytes and ferns included 64 species in 37 genera and 16 families. Fabaceae $(55 \mathrm{spp}$.) was the family with the highest number of species, followed by Rubiaceae ( $50 \mathrm{spp}$.), Melastomataceae (28 spp.), Bignoniaceae and Orchidaceae (27 spp. each) and Myrtaceae (25 spp.). Once the survey was concluded, a comparison between it and the floristic composition of other nine areas ( 3 of seasonal and 6 of dense ombrophilous forest) was performed through multivariate analysis. These 9 sites were chosen as their surveys also included all angiosperm habits rather
\end{abstract}

Este artigo possui material adicional em sua versão eletrônica.

\footnotetext{
${ }^{1}$ Jardim Botânico do Rio de Janeiro, R. Pacheco Leão 915, 22460-030, Rio de Janeiro, RJ, Brasil.

${ }^{2}$ Universidade Federal do Vale do São Francisco, Campus de Ciências Agrárias, Colegiado de Ciências Biológicas, Rod. BR 407 km 12 , Lote 543 Projeto de Irrigação Senador Nilo Coelho s/nº - C1, 56.300-990, Petrolina, PE, Brasil.

${ }^{3}$ Universidade Federal de Minas Gerais, Inst. Ciências Biológicas, Depto. Botânica, Av. Antônio Carlos 6627, 31270-901, Belo Horizonte, MG, Brasil.

${ }^{4}$ Universidade de São Paulo, Escola de Artes, Ciências e Humanidades, Av. Arlindo Béttio 1000, 03828-000, São Paulo, SP, Brasil.

${ }^{5}$ Universidade Tecnológica Federal do Paraná, Depto. Engenharia Ambiental, Av. dos Pioneiros 3131, 86036-370, Londrina, PR, Brasil.

${ }^{6}$ Universidade Federal de Juiz de Fora, ICB, Depto. Botânica, 36330-900, Juiz de Fora, MG, Brasil.

${ }^{7}$ Instituto de Botânica, Av. Miguel Estéfano 3687, 04301-012, São Paulo, SP, Brasil.

${ }^{8}$ Autores para correspondência: danielfloristico@yahoo.com.br; rafaela@jbrj.gov.br
} 
than only woody plants. Each analysis was processed for the all habits and then for each one of the following 8 habits: trees (including treelets), shrubs, climbers (woody and herbaceous), ground-dwelling herbs, rupicolous herbs, epiphytes, hemiepiphytes, and parasites. Multivariate analysis suggested that the longitudinal, latitudinal and altitudinal gradients interfere in different ways over the species richness of diverse habits. The reduced number of species shared between areas, associated to the high regional richness of certain habits shows the importance of conserving forest fragments in different geographical areas of the Atlantic Forest in order to maximize the conservation of the biodiversity within this Domain.

Key words: floristic composition, Atlantic Forest Domain, Zona da Mata.

\section{Introdução}

A despeito da grande perda de sua cobertura vegetal, a Floresta Atlântica ainda abriga cerca de 14.552 espécies de plantas vasculares, das quais mais da metade são endêmicas, sendo que anualmente uma média de 170 são descritas como novas para a ciência (Tabarelli et al. 2005; Ribeiro et al. 2009; Stehmann et al. 2009; Sobral \& Stehmann 2009; Werneck et al. 2011). A grande diversidade biológica presente neste Domínio deve-se, entre outras razões, à ampla distribuição norte-sul, à existência de consideráveis diferenças geológicas e altitudinais, além das grandes transformações que a região sofreu em função das intensas mudanças climáticas pelas quais passou em distintos períodos geológicos (Oliveira-Filho \& Fontes 2000; Lino 2009). O Domínio Atlântico também apresenta variações florísticas muito maiores que os demais domínios brasileiros, sendo as classificações para as diferentes formações encontradas nessa região baseadas em padrões fisionômicos, ecológicos e florísticos (Leitão-Filho 1987).

A discussão sobre a amplitude latitudinal e a identidade florística entre formações ombrófilas e estacionais no Domínio Atlântico é controvertida, provocando divergências na aplicação de terminologias adequadas e no reconhecimento das suas fitofisionomias, particularmente em regiões transicionais (Fernandes 2003; OliveiraFilho \& Fontes 2000; Oliveira-Filho 2009). Nas últimas décadas, a utilização de métodos numéricos multivariados tem auxiliado na definição de relações entre as formações florestais, estabelecendo relações florísticas quantitativas, contribuindo para a compreensão das relações entre os diferentes tipos de vegetação e os limites da Floresta Atlântica (Silva \& Shepherd 1986; Oliveira-Filho 1993; Oliveira-Filho \& Ratter 1995; Araújo 1998; Scudeller 2002). Porém, esses estudos abordaram, na sua maioria, somente o estrato arbóreo em um contexto regional, ou trataram apenas de um tipo de formação florestal (Gentry 1990; Oliveira-Filho et al., 1994a,b, 2005; Salis et al. 1995; Torres et al. 1997; Oliveira-Filho \& Fontes 2000; Scudeller et al. 2001; Pereira et al. 2007; Murray-Smith et al. 2008), explorando assim apenas uma parte da composição e dos relacionamentos existentes.

A região da Zona da Mata de Minas Gerais era constituída por um maciço florestal composto por florestas estacionais semidecíduas montanas e submontanas que atualmente se encontram extremamente fragmentadas. Diversos tipos de ações antrópicas estiveram associados ao processo de fragmentação florestal regional, como a agricultura cafeeira, a pecuária, a retirada seletiva de madeira, a mineração, o fogo e o crescente desenvolvimento das áreas urbanas (Heringer 1947; Oliveira-Filho et al. 1994b; Meira Neto et al. 1997; Silva 2000). Em julho de 1824, Grigory Ivanovitch Langsdorff esteve no local onde hoje está inserido o município de Descoberto, alguns meses após a descoberta de ouro. Em seus diários, o expedicionário e cônsul-geral da Rússia no Brasil mencionou que o ouro foi encontrado pela primeira vez por um agricultor, num pequeno riacho em sua propriedade. A notícia espalhou-se em pouco tempo e trouxe para o local pessoas dos cantos mais remotos da província de Minas Gerais (Tinôco et al. 2010). A corrida pelo ouro provocou as primeiras alterações na paisagem, interrompendo a continuidade do maciço florestal existente, algo que se agravou com a economia cafeeira e agropastoril subsequente (Almeida 2000). Dentro deste cenário de destruição, a Reserva Biológica da Represa do Grama no município de Descoberto é um dos remanescentes mais significativos de floresta estacional semidecidual da Zona da Mata de Minas Gerais.

Inventários que consideram todos os hábitos, com listagens de espécies confiáveis e com aspectos fitogeográficos mensuráveis são fundamentais na compreensão das relações existentes entre as fisionomias que compõem o Domínio Atlântico. 
Esses levantamentos ainda são escassos devido principalmente ao longo período de tempo necessário para obter espécimes férteis que abarquem a diversidade de hábitos ocorrentes em florestas tropicais. Da mesma forma, as relações florísticas dos diferentes hábitos entre as formações florestais estacionais e as florestas ombrófilas no sudeste brasileiro são ainda pouco explorados. Assim, o presente trabalho tem como objetivos: (a) disponibilizar a listagem de espécies de plantas vasculares ocorrentes na ReBio do Grama; (b) verificar as relações florísticas desta com outras áreas de diferentes fitofisionomias do Domínio Atlântico no sudeste brasileiro e (c) avaliar se os padrões de distribuição florística são similares ao considerar cada hábito separadamente. Espera-se assim contribuir para enriquecer o conhecimento da flora de Minas Gerais e também melhorar a compreensão das relações florísticas nas diferentes áreas do Domínio Atlântico.

\section{Material e Métodos}

A Reserva Biológica da Represa do Grama localiza-se no município de Descoberto, na Zona da Mata mineira, entre as coordenadas $21^{\circ} 20^{\prime} 50^{\prime \prime}-21^{\circ} 26^{\prime} 30^{\prime \prime}$ 'S e $42^{\circ} 55^{\prime} 20^{\prime \prime}-42^{\circ} 58^{\prime} 15^{\prime \prime} \mathrm{W}$, distante cerca de $100 \mathrm{~km}$ a nordeste de Juiz de Fora (Fig. 1). Abrange um fragmento de 263,8 ha de Floresta Estacional Semidecídua Submontana (sensu Veloso et al. 1991) que ocorre sobre um relevo montanhoso com altitudes que variam entre 500 e $720 \mathrm{~m}$ e que predominam em relação às áreas de planalto, baixadas e várzeas, onde ocorrem formações aluviais. O clima é do tipo Cwb, segundo a classificação de Köppen, as médias anuais de temperatura e precipitação são de $22,3^{\circ} \mathrm{C}$ e $1.550 \mathrm{~mm}$, respectivamente, e a estação de seca se dá entre maio e setembro (Embrapa 2003). A área foi a primeira Reserva Biológica criada em Minas Gerais, em 1971, e abriga seis nascentes que desembocam em dois córregos que são fonte de captação de água para abastecimento parcial dos municípios de Descoberto e São João Nepomuceno. O ribeirão do Grama, que margeia a ReBio, pertencente à sub-bacia do rio Pomba e afluente da bacia do Paraíba do Sul (Scolforo et al. 2008).

O levantamento florístico da ReBio do Grama foi realizado por meio de expedições de campo quinzenais com duração de três a quatro dias, realizadas entre agosto de 1999 e dezembro de 2004. As coletas foram realizadas amostrando apenas espécimes férteis, notificando para cada um o local onde foi encontrado e os dados que são perdidos no processo de herborização. Todas as coleções oriundas do projeto encontram-se depositadas nos herbários da Universidade Federal de Juiz de Fora (CESJ) e no Jardim Botânico do Rio de Janeiro (RB). As duplicatas foram enviadas a diversos especialistas que contribuíram para uma determinação mais acurada dos espécimes, cujos nomes constam no Apêndice (ver versão eletrônica). Famílias cujos especialistas não estão indicados foram identificadas pelos autores deste trabalho. A lista de espécies de angiospermas é apresentada de acordo com APG III (2009), a de samambaias segundo Smith et al. (2006) e Rothfels et al. (2012) e a de licófitas segundo Kramer \& Green (1990). Todos os táxons tiveram suas distribuições e autores padronizados segundo a Lista de Espécies da Flora do Brasil (2012).

As nove áreas selecionadas para efetuar as análises comparativas foram escolhidas por apresentarem listagens completas de angiospermas, com seus respectivos hábitos, e por seguirem metodologias similares em relação ao esforço amostral despendido. As samambaias e licófitas não foram incluídas nas análises. Em três áreas do estado de Minas Gerais (Juiz de Fora, Caratinga e o Parque Estadual do Rio Doce) predominam as

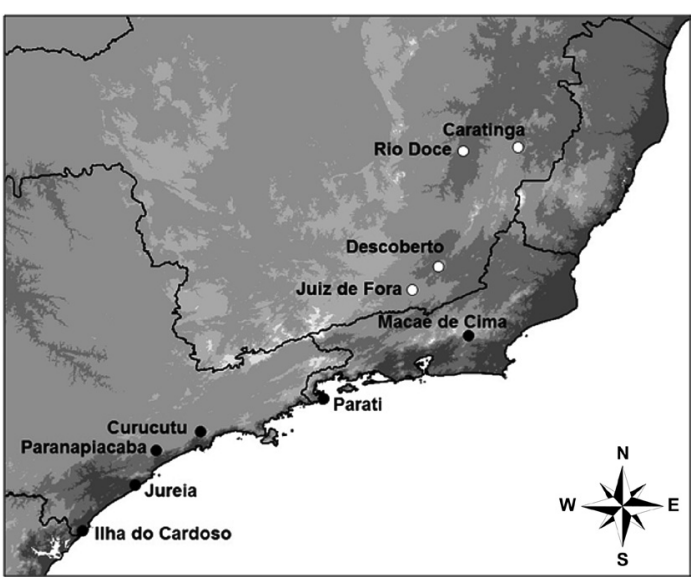

Figura 1 - Distribuição geográfica das 10 localidades cujas listagens florísticas foram utilizadas nas análises multivariadas em escala de 1: 50.000. Círculos vazios e cheios são áreas onde predominam, respectivamente, florestas estacionais semideciduais e florestas ombrófilas densas.

Figure 1 - Geographic distribution of the 10 localities whose floristic lists were used in multivariate analyzes. Empty circles and full circles are areas dominated, respectively, by semideciduous forests and tropical rainforests. 
florestas estacionais semidecíduas (sensu Veloso et al. 1991). Nas outras seis predominam as florestas ombrófilas densas que ocupam as encostas das serras litorâneas nos estados de São Paulo (Ilha do Cardoso, Núcleo Curucutu, Estação Ecológica Jureia-Itatins e Serra de Paranapiacaba) e Rio de Janeiro (Macaé de Cima e Parati). As áreas de Minas Gerais estão situadas mais ao norte e foram tratadas como setentrionais enquanto as áreas de São Paulo e do Rio de Janeiro, encontradas mais ao sul, foram tratadas como meridionais (Fig.1, Tab. 1).

Para possibilitar uma maior precisão nas análises, foi feita uma criteriosa verificação das listas florísticas para as 10 áreas, onde todas as espécies compiladas passaram por uma verificação de sinonímias. Posteriormente, a compilação passou pela categorização em hábitos de crescimento onde foi respeitada a informação contida nas etiquetas das amostras, na literatura e fornecida pelos respectivos especialistas consultados. Com isso, definiram-se os seguintes hábitos para as análises: árvores (incluindo arvoretas e palmeiras de grande porte), arbustos, trepadeiras (lenhosas e herbáceas), ervas terrícolas, ervas saxícolas, epífitas, hemiepífitas e parasitas. Somente então foi construída a matriz binária de ocorrência das espécies que foi submetida a uma ordenação, por meio de uma análise de correspondência distendida (ACD), e a uma análise de agrupamento usando o índice de Bray-Curtis como medida de similaridade florística e médias ponderadas como técnica de agrupamento (Felfili et al. 2011). As ACD foram processadas no software PCORD 6.0 (McCune \& Mefford 2011) e as análises de agrupamento no software PAST 1.93 (Hammer et al. 2001). Cada par de análises foi processado para o conjunto total das espécies e para os oito subconjuntos correspondentes aos hábitos.

Com o propósito heurístico de auxiliar a indução de interpretações a posteriori, variáveis bioclimáticas foram selecionadas para as dez áreas sendo extraídas do software TreeAtlan 2.0 (www.icb.ufmg.br/treeatlan) e representadas nos diagramas das ACD como vetores de tamanho proporcional às suas correlações com os escores de ordenação nos dois primeiros eixos das ACD. Conforme consta nas Figs. 2 e 3 destacaram-se por suas significâncias estatísticas as seguintes variáveis bioclimáticas; duração da seca (em meses), temperatura anual (em graus Celsius),

Tabela 1 - Localidades do Domínio Atlântico cujas listagens florísticas foram utilizadas nas análises de correspondência distendida (ACD) e análises de agrupamento.

Table 1 - Atlantic Domain locations of the floristic lists used for distended correspondence analysis (DCA) and cluster analysis.

\begin{tabular}{|c|c|c|c|c|c|c|}
\hline Localidade & Nome resumido & Coordenadas geográficas & Municípios \& estado & $\begin{array}{l}\text { Altitude } \\
\text { (m) }\end{array}$ & $\begin{array}{c}\text { Esforço } \\
\text { amostral } \\
\text { (anos de } \\
\text { coleta } \\
\end{array}$ & Referências \\
\hline Rebio do Grama & Descoberto & $\begin{array}{l}21^{\circ} 20^{\prime} 50^{\prime \prime}-21^{\circ} 26^{\prime} 30^{\prime \prime} \mathrm{S} \\
42^{\circ} 55^{\prime} 20^{\prime \prime}-42^{\circ} 58^{\prime} 15^{\prime \prime} \mathrm{W}\end{array}$ & Descoberto, MG & Até 720 & 5 & Este trabalho \\
\hline Morro do Imperador & Juiz de Fora & $\begin{array}{l}21^{\circ} 34^{\prime}-22^{\circ} 05^{\prime} \mathrm{S} \\
43^{\circ} 09^{\prime}-43^{\circ} 45^{\prime} \mathrm{W}\end{array}$ & Juiz de Fora, MG & Até 900 & 3 & Pifano et al. 2007 \\
\hline $\begin{array}{l}\text { Parque Estadual do } \\
\text { Rio Doce }\end{array}$ & Rio Doce & $\begin{array}{c}19^{\circ} 29^{\prime}-19^{\circ} 48^{\prime} \mathrm{S} \\
42^{\circ} 28^{\prime}-42^{\circ} 38^{\prime} \mathrm{W}\end{array}$ & $\begin{array}{c}\text { Marliéria, Dionísio e } \\
\text { Timóteo, MG }\end{array}$ & Até 680 & 13 & $\begin{array}{l}\text { Lombardi \& Gonçalves } \\
\qquad 2000\end{array}$ \\
\hline $\begin{array}{c}\text { Estação Ecológica de } \\
\text { Caratinga }\end{array}$ & Caratinga & $19^{\circ} 50^{\prime} \mathrm{S}-41^{\circ} 50^{\prime} \mathrm{W}$ & Caratinga, $\mathrm{MG}$ & Até 680 & 5 & $\begin{array}{l}\text { Lombardi \& Gonçalves } \\
\qquad 2000\end{array}$ \\
\hline Ilha do Cardoso & Ilha do Cardoso & $\begin{array}{l}25^{\circ} 03^{\prime} 05^{\prime \prime}-25^{\circ} 18^{\prime} 18^{\prime \prime} \mathrm{S} \\
47^{\circ} 53^{\prime} 48^{\prime \prime}-48^{\circ} 05^{\prime} 42^{\prime \prime} \mathrm{W}\end{array}$ & Cananéia, SP & Até 950 & 9 & Melo et al. 1991 \\
\hline Serra da Juréia & Juréia & $\begin{array}{c}24^{\circ} 17^{\prime}-24^{\circ} 40^{\prime} \mathrm{S} \\
47^{\circ} 00^{\prime}-47^{\circ} 360^{\prime} \mathrm{W}\end{array}$ & $\begin{array}{l}\text { Iguape, Peruíbe, } \\
\text { Itariri, Pedro de } \\
\text { Toledo e Miracatu, SP }\end{array}$ & Até 800 & 6 & Mamede et al. 2001 \\
\hline Núcleo Curucutu & Curucutu & $\begin{array}{l}23^{\circ} 59^{\prime} \mathrm{S}-46^{\circ} 44^{\prime} \mathrm{W} \\
24^{\circ} 07^{\prime}-46^{\circ} 46^{\prime} \mathrm{W}\end{array}$ & $\begin{array}{c}\text { Itanhaém, Juquitiba e } \\
\text { São Paulo, SP }\end{array}$ & Até 790 & 7 & Garcia \& Pirani 2005 \\
\hline Serra de Paranapiacaba & Paranapiacaba & $\begin{array}{l}23^{\circ} 46^{\prime} 00^{\prime \prime}-23^{\circ} 47^{\prime} 10^{\prime \prime} \mathrm{S} \\
46^{\circ} 18^{\prime} 20^{\prime \prime}-46^{\circ} 20^{\prime \prime} 40^{\prime \prime} \mathrm{W}\end{array}$ & Santo André, SP & Até 900 & 5 & Kirizawa et al. 2003 \\
\hline Macaé de Cima & Macaé de Cima & $\begin{array}{l}22^{\circ} 21^{\prime}-22^{\circ} 28^{\prime} \mathrm{S} \\
42^{\circ} 27^{\prime}-42^{\circ} 35^{\prime} \mathrm{W}\end{array}$ & Nova Friburgo, RJ & Até 1720 & 4 & $\begin{array}{c}\text { Lima \& Guedes-Bruni } \\
1997\end{array}$ \\
\hline Parati & Parati & $\begin{array}{l}23^{\circ} 10^{\prime}-23^{\circ} 23^{\prime} \mathrm{S} \\
44^{\circ} 30^{\prime}-44^{\circ} 51^{\prime} \mathrm{W}\end{array}$ & Parati, RJ & Até 1300 & 6 & Marques 1997 \\
\hline
\end{tabular}




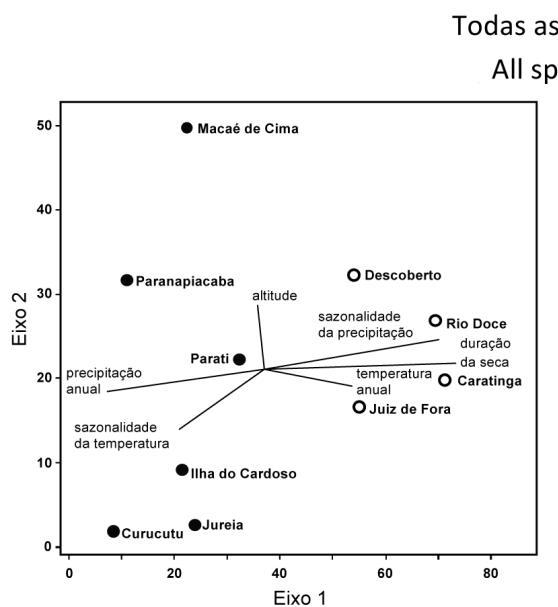

odas as espécies

All species

Espécies arbóreas
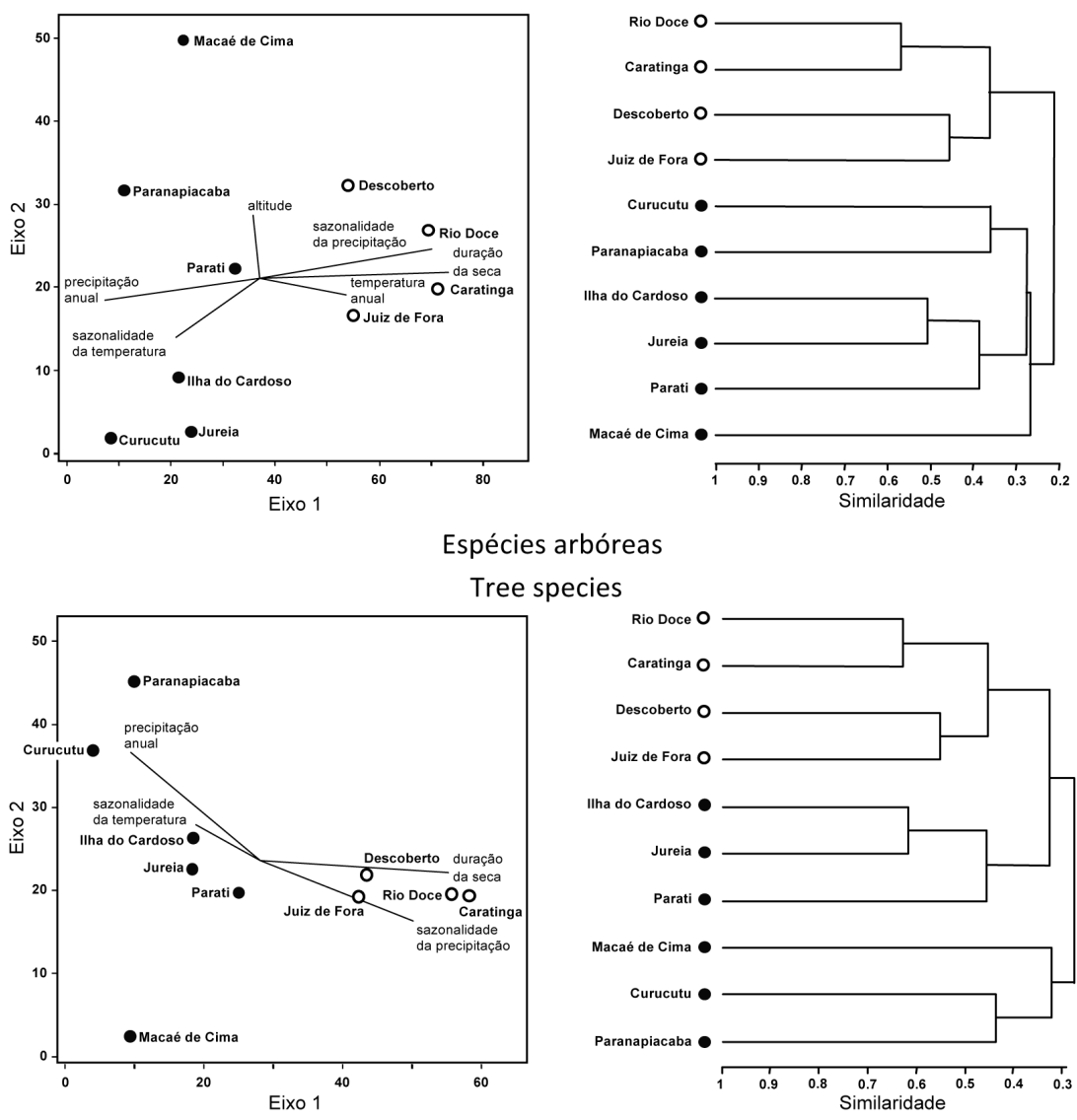

Tree species

Espécies arbustivas

Shrub species
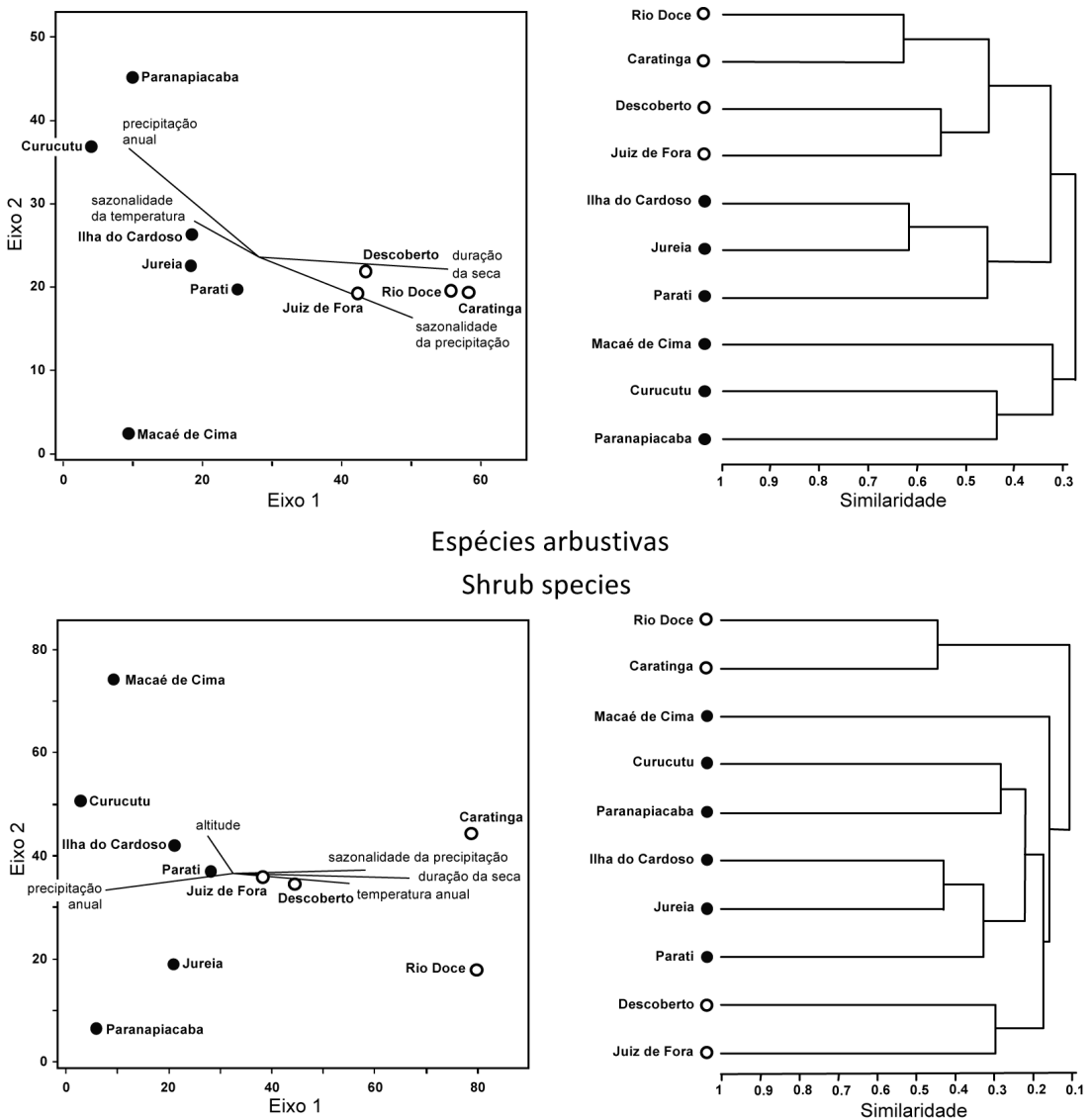

Figura 2 - Análises multivariadas das dez listagens florísticas mostrando, do lado esquerdo, a ordenação das localidades por análise de correspondência distendida $(\mathrm{ACD})$ e, do lado direito, o dendrograma de classificação das mesmas áreas obtido por análise de agrupamento. (a) Todas as espécies, (b) espécies arbóreas e (c) espécies arbustivas. Círculos vazios e cheios são áreas onde predominam, respectivamente, florestas estacionais semideciduais e florestas ombrófilas densas.

Figure 2 - Multivariate analyzes of the ten floristic lists showing on the left side, the ordering of the locations for extended correspondence analysis (DCA) and on the right, the dendrogram classification of the same areas obtained by cluster analysis. (a) All species, (b) tree species and (c) shrub species. Empty circles and full circles are areas dominated, respectively, by semideciduous forests and tropical rainforests. 
Espécies trepadeiras

Vine species
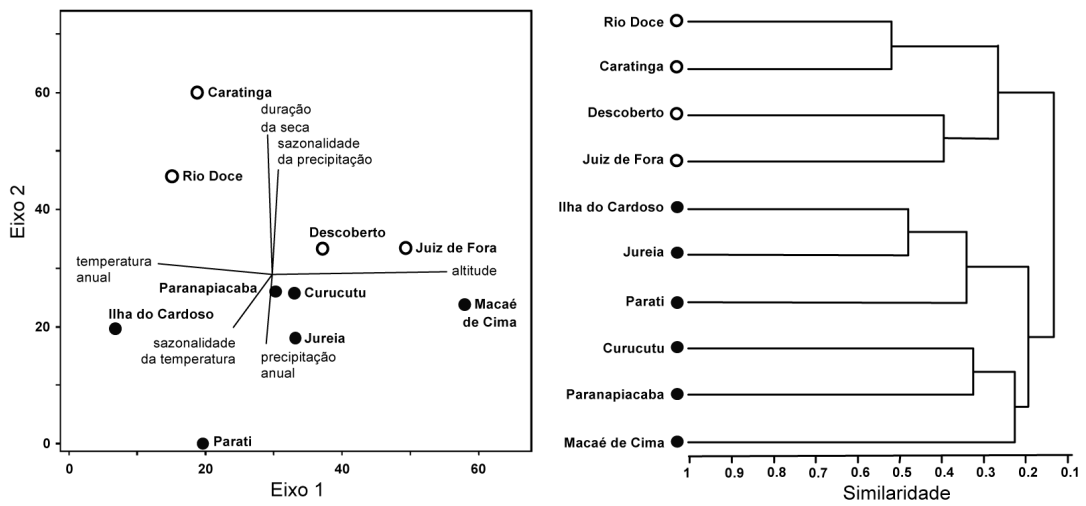

Espécies herbáceas terrícolas

Terrestrial herbaceous species
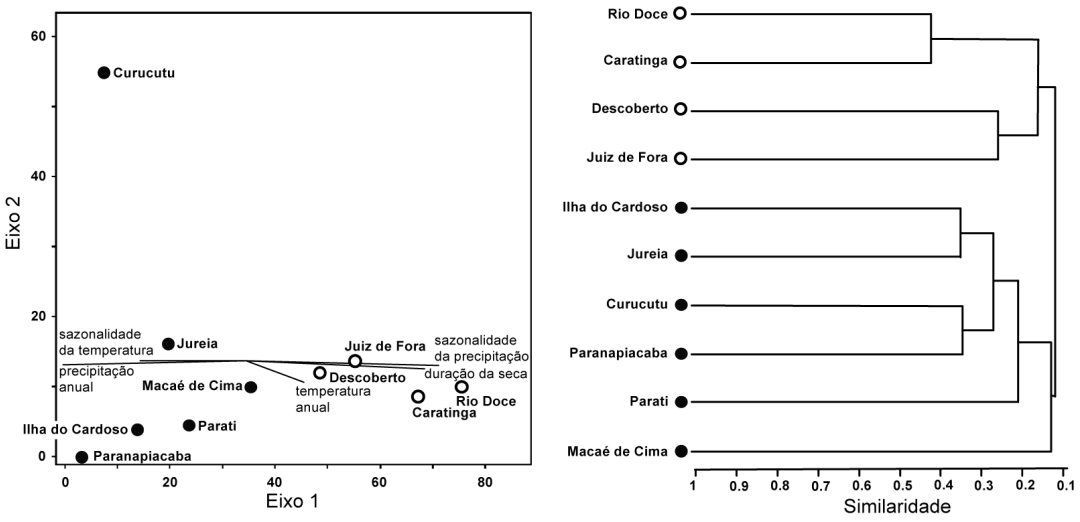

Espécies herbáceas saxícolas

Rupiculous species
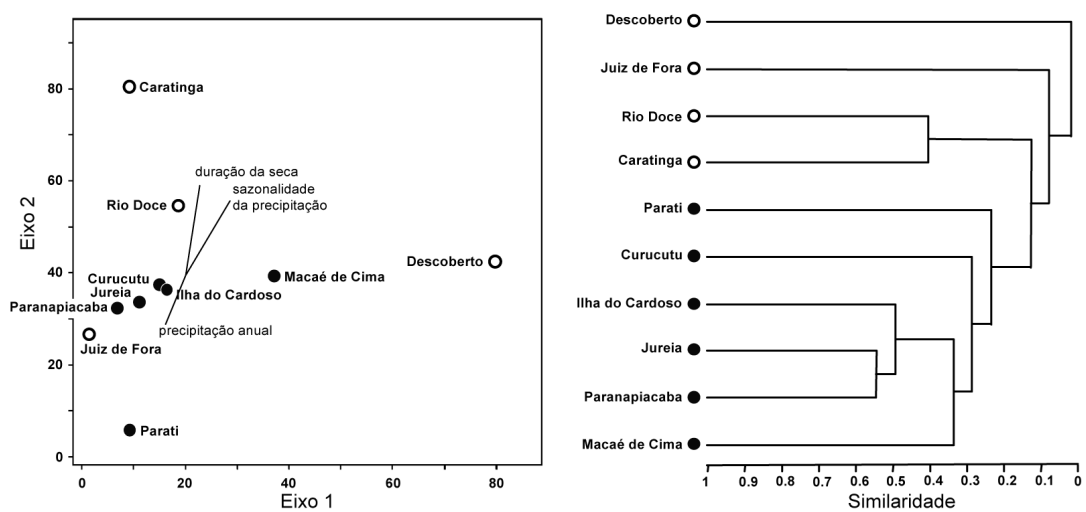

Figura 3 - Análises multivariadas das dez listagens florísticas mostrando, do lado esquerdo, a ordenação das localidades por análise de correspondência distendida $(\mathrm{ACD})$ e, do lado direito, o dendrograma de classificação das mesmas áreas obtido por análise de agrupamento. (a) Espécies trepadeiras, (b) espécies herbáceas terrícolas e (c) espécies herbáceas saxícolas. Círculos vazios e cheios são áreas onde predominam, respectivamente, florestas estacionais semideciduais e florestas ombrófilas densas.

Figure 3 - Multivariate analyzes of the ten floristic lists showing the left side, the ordering of the locations for extended correspondence analysis (DCA) and the right, the dendrogram classification of the same areas obtained by cluster analysis. (a) vine species, (b) terrestrial herbaceous species and (c) Rupiculous herbaceous species. Empty circles and full circles are areas dominated, respectively, semideciduous forests and tropical rainforests. 
sazonalidade da temperatura (somatório das temperaturas na época de estiagem) e a precipitação anual (somatório das precipitações ao longo do ano em milímetros de mercúrio). Vale resaltar que a altitude não foi considerada como variável bioclimática em si, mas como variável geográfica. A significância dos autovalores dos eixos de ordenação foi avaliada em testes de permutação com 999 reamostragens. Para avaliação das correlações entre as medidas de similaridade florísticas e as distâncias entre as áreas foi aplicado um teste de Mantel (McCune \& Mefford 2011) através de índices de Bray-Curtis.

\section{Resultados e Discussão}

Foram coletadas na ReBio do Grama 644 espécies de angiospermas, distribuídas em 370 gêneros e 100 famílias, e 64 espécies de licófitas e samambaias, pertencentes a 37 gêneros e 16 famílias. Entre as samambaias e licófitas, Polypodiaceae foi a família que teve maior riqueza específica, seguida de Pteridaceae. Os gêneros com maior riqueza foram Thelypteris, seguido por Anemia, Pecluma e Pteris, sendo a maioria dos gêneros (68\%) representado por uma única espécie (ver Apêndices 1 e 2 na versão eletrônica).

Analisando a proporção de epífitas entre as samambaias e licófitas encontradas na ReBio do Grama, verificou-se que estas corresponderam a $36 \%$ do total de espécies. Este percentual está mais próximo do encontrado nas florestas ombrófilas densas do sudeste e sul do Brasil, onde a riqueza de epífitas criptogâmicas é comumente elevada (Sylvestre 1997; Dittrich et al. 2005). Levantamentos florísticos realizados em florestas estacionais semidecíduas em Minas Gerais indicam um percentual menor de epífitas: 23,03\% na APA Fernão Dias (Melo \& Salino 2007); 13,7\% (Figueiredo \& Salino 2005); 8,25\% no Parque Estadual do Rio Doce e 8,42\% na Estação Biológica da Caratinga (Melo \& Salino 2002). Além disso, foi registrada a presença de espécies que são mais frequentes em florestas ombrófilas costeiras e que raramente figuram em florestas estacionais, como Asplenium mucronatum, Dicranoglossum furcatum e Diplazium mutilum.

Seis espécies de angiospermas foram reconhecidas como novas para a ciência: Calyptranthes detecta, Cupania ludowigii, Dorstenia mariae, Myrcia clavija, Tetracera forzzae, e Unonopsis bauxitae (Sommer \& Ferrucci 2004; Lobão et al. 2005; Sobral 2006;
Fraga \& Aymard 2007; Sobral et al. 2012). As espécies Malanea fosteronioides, Philodendron curvilobum, Neoregelia farinosa, Nidularium longiflorum e Quesnelia quesneliana, espécies típicas das formações ombrófilas, foram registradas pela primeira vez em Minas Gerais a partir do material coletado na ReBio (Almeida et al. 2005; Matozinhos \& Konno 2008; Versieux \& Wendt 2006). Já Schefflera longipetiolata, Caryocar edule, Tovomita bahiensis, Besleria meridionalis, Beilschmiedia taubertiana e Wullschlaegelia aphylla foram indicadas como plantas raras, e dentre estas algumas eram conhecidas apenas por coleções do século XIX (Menini Neto et al. 2004; Assis et al. 2005; Pivari et al. 2005; Farinazzo \& Salimena 2007). Dentre as espécies de angiospermas inventariadas no presente estudo, 47 não foram citadas como ocorrentes em Minas Gerais no Catálogo de Plantas e Fungos do Brasil (Forzza et al. 2010), demonstrando que inventários regionais de longa duração são fundamentais para o conhecimento sobre a distribuição geográfica da espécies.

Fabaceae foi a família com maior diversidade específica $(8,54 \%$ da riqueza total), seguida por Rubiaceae $(7,76 \%)$, Melastomataceae (4,34\%), Orchidaceae e Bignoniaceae (4,19\% cada) e Myrtaceae (3,88\%). Estas seis famílias juntas perfizeram $33 \%$ da riqueza florística de angiospermas registradas na ReBio. Os gêneros mais representativos foram Psychotria, Solanum, Piper, Miconia, Machaerium, Myrcia e Leandra (ver Apêndice 2 na versão eletrônica). Tanto estas famílias quanto estes gêneros também estão entre os de maior riqueza específica na Floresta Atlântica como um todo (Stehmann et al. 2009).

No total das 10 áreas analisadas foram listadas 3.430 espécies de angiospermas, sendo 1.437 árvores, 584 arbustos, 500 ervas terrícolas, 54 ervas saxícolas, 320 epífitas, 32 hemiepífitas, 483 trepadeiras e 21 parasitas. Conforme esperado houve repetição das famílias e gêneros (Tabs. 2 e 3) de angiospermas mais representativas em todas as 10 áreas comparadas, principalmente em relação às arvores, alterando apenas a posição em relação ao número de espécies (Tab. 4). As árvores representaram $41,9 \%$ do total de espécies listadas, denotando sua importância para a riqueza total da Floresta Atlântica. Somente 10 espécies arbóreas estiveram presentes em todos os levantamentos (Euterpe edulis, Sloanea hirsuta, Pera glabrata, Senna multijuga, Endlicheria paniculata, 


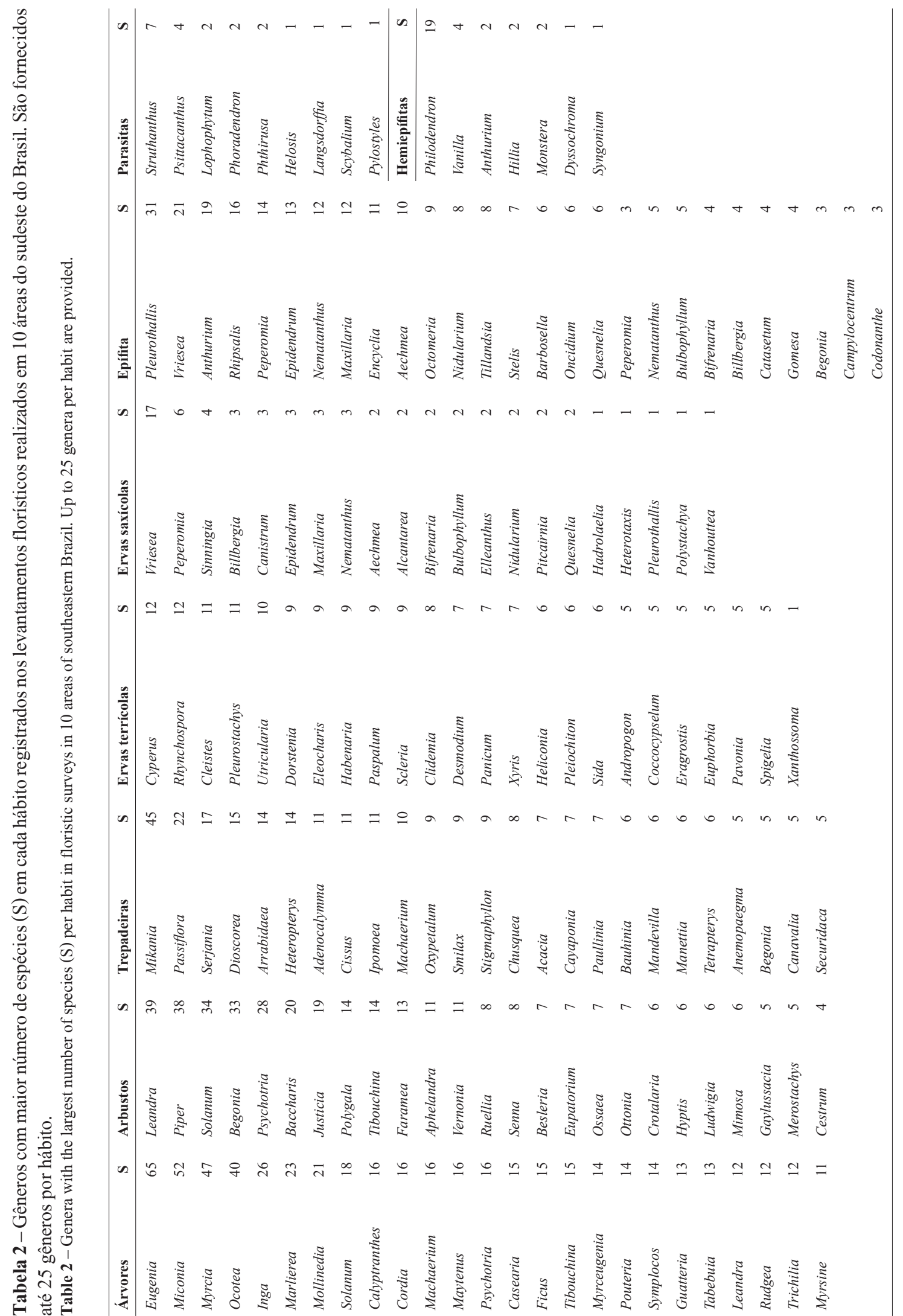


Tabela 3 - Riqueza encontrada em cada hábito distribuída nas formações ombrófilas e semidecíduas comparadas, bem como o compartilhamento de espécies destas formações com a composição florística da Reserva Biologica da Represa do Grama (Rebio Grama).

Table 3 - Richness found in each life form distributed in rainforests and compared semideciduous forests as well as the sharing of species of these formations with the floristic composition of the Biological Reserve of Grama (Grama Rebio).

\begin{tabular}{|c|c|c|c|c|c|c|c|c|c|}
\hline \multirow[t]{2}{*}{ Hábito } & \multicolumn{2}{|c|}{ ReBio Grama } & \multicolumn{2}{|c|}{ Florestas Ombrófilas } & \multicolumn{2}{|c|}{$\begin{array}{c}\text { Florestas } \\
\text { Semidecíduas }\end{array}$} & \multicolumn{3}{|c|}{$\begin{array}{l}\text { Compartilhamento } \\
\text { com a ReBio Grama }\end{array}$} \\
\hline & $\begin{array}{l}\text { Riqueza } \\
\text { Total }\end{array}$ & Exclusivas & $\begin{array}{l}\text { Riqueza } \\
\text { Total }\end{array}$ & Exclusivas & $\begin{array}{c}\text { Riqueza } \\
\text { Total }\end{array}$ & Exclusivas & $\begin{array}{l}\text { Floresta } \\
\text { Ombrófila }\end{array}$ & $\begin{array}{c}\text { Floresta } \\
\text { Semidecídua }\end{array}$ & $\begin{array}{l}\text { Ambas as } \\
\text { formações }\end{array}$ \\
\hline Árvore & 363 & 42 & 564 & 92 & 873 & 401 & 35 & 71 & 257 \\
\hline Arbusto & 82 & 27 & 419 & 333 & 251 & 165 & 17 & 15 & 23 \\
\hline Trepadeira & 104 & 25 & 339 & 235 & 248 & 144 & 23 & 28 & 28 \\
\hline Erva Terrestre & 66 & 20 & 358 & 327 & 183 & 152 & 20 & 9 & 17 \\
\hline Parasita & 4 & 0 & 13 & 6 & 8 & 2 & 2 & 1 & 0 \\
\hline Erva Saxícola & 4 & 2 & 50 & 44 & 10 & 4 & 2 & 0 & 0 \\
\hline Epífita & 41 & 7 & 297 & 266 & 45 & 14 & 24 & 3 & 7 \\
\hline Hemiepífita & 11 & 3 & 24 & 18 & 14 & 8 & 4 & 4 & 8 \\
\hline
\end{tabular}

Cabralea canjerana, Myrcia splendens, Guapira opposita, Zanthoxylum rhoifolium e Cecropia glaziovii), enquanto nenhuma espécie dos hábitos restantes esteve presente em mais de oito levantamentos. Houve predomínio de espécies com distribuição restrita a um ou dois levantamentos em todos os hábitos, e a porcentagem desta distribuição restrita varia de $61,5 \%$ nas arbóreas a $82,5 \%$ nos arbustos.

Os testes de Mantel (Tab. 5) demonstraram uma correlação significativa entre a distância geográfica e a similaridade florística entre as áreas, exceto no caso da flora herbácea saxícola. A análise com os diferentes hábitos das espécies registradas na ReBio do Grama demonstrou um frequente agrupamento com a do Morro do Imperador (Juiz de Fora), ambas áreas da Zona da Mata mineira. Estas duas áreas juntas se agruparam com as demais localidades de florestas estacionais para a maioria dos hábitos, o que sugere um grupo claramente distinto daquele composto pelas florestas ombrófilas (Figs. 2a-b, 3a-b, 4b). Nas florestas estacionais, a flora completa, as árvores, os arbustos, as trepadeiras e as herbáceas terrícolas demonstraram maior similaridade entre si do que com os levantamentos de florestas ombrófilas, sugerindo a ocorrência de gradientes longitudinais.
Dentre os levantamentos de florestas ombrófilas, tanto a Ilha do Cardoso como a Jureia, no sul do estado de São Paulo, geralmente apareceram associadas com Parati, no sul do estado do Rio de Janeiro, todas em planícies e montanhas litorâneas sob forte influência do oceano Atlântico. Curucutu e Paranapiacaba, ambas no Planalto Paulista, emergiram frequentemente associadas para a maioria dos hábitos analisados. Macaé de Cima, na região serrana do Rio de Janeiro, foi a área que mais variou dentre os dendrogramas, ora se relacionando com florestas estacionais, ora com florestas ombrófilas. Essas relações florísticas estão associadas ao gradiente altitudinal do sudeste brasileiro e também aos centros de endemismos que ocorrem principalmente na Ilha do Cardoso e na Serra da Juréia (Mori et al, 1981; MurraySmith et al. 2008), que possibilitam um maior compartilhamento de espécies entre áreas com altitudes similares, principalmente para aquelas na mesma região geomorfológica (Meira-Neto \& Martins 2002).

As análises de ordenação (Figs. 2 a 4) sugeriram níveis distintos de dicotomia entre a flora de florestas estacionais e a de florestas ombrófilas para os diferentes hábitos. Na região sul da Zona da Mata de Minas Gerais ocorrem os tipos 
Tabela 4 - Famílias com maior número de espécies (S) em cada hábito registradas nos levantamentos florísticos realizados em 10 áreas do sudeste do Brasil. São fornecidas até 20 famílias por forma de crescimento.

Table 4 - Families with the largest number of species (S) in each habit in the floristic surveys in 10 areas of southeastern Brazil. Up to 20 families per habit are provided.

\begin{tabular}{|c|c|c|c|c|c|c|c|c|c|c|c|}
\hline Árvores & $\mathbf{S}$ & Arbustos & $\mathbf{S}$ & Trepadeiras & $\mathbf{S}$ & Ervas terrícolas & $\mathbf{S}$ & Ervas saxícolas & $\mathbf{S}$ & Hemiepífitas & $\mathbf{S}$ \\
\hline Myrtaceae & 211 & Asteraceae & 91 & Bignoniaceae & 62 & Poaceae & 78 & Bromeliaceae & 33 & Araceae & 25 \\
\hline Fabaceae & 148 & Melastomataceae & 69 & Asteraceae & 50 & Cyperaceae & 69 & Gesneriaceae & 5 & Orchidaceae & 4 \\
\hline Melastomataceae & 90 & Acanthaceae & 59 & Fabaceae & 50 & Orchidaceae & 60 & Orchidaceae & 16 & Rubiaceae & 2 \\
\hline Lauraceae & 85 & Rubiaceae & 59 & Apocynaceae & 46 & Asteraceae & 20 & Piperaceae & 6 & Solanaceae & 1 \\
\hline Rubiaceae & 74 & Solanaceae & 49 & Malpighiaceae & 46 & Rubiaceae & 18 & \multicolumn{2}{|l|}{ Totais: 4 famílias } & \multicolumn{2}{|l|}{ Totais: 4 famílias } \\
\hline Euphorbiaceae & 45 & Piperaceae & 45 & Sapindaceae & 33 & Melastomataceae & 17 & \multicolumn{2}{|l|}{20 gêneros } & \multicolumn{2}{|l|}{8 gêneros } \\
\hline Annonaceae & 43 & Fabaceae & 35 & Passifloraceae & 24 & Fabaceae & 16 & \multicolumn{2}{|l|}{60 espécies } & \multicolumn{2}{|l|}{32 espécies } \\
\hline Sapotaceae & 32 & Begoniaceae & 33 & Cucurbitaceae & 23 & Marantaceae & 15 & & & & \\
\hline Celastraceae & 29 & Polygalaceae & 14 & Convolvulaceae & 19 & Malvaceae & 14 & & & & \\
\hline Solanaceae & 29 & Euphorbiaceae & 11 & Dioscoriaceae & 16 & Amaryllidaceae & 11 & Epífitas & $\mathbf{S}$ & Parasitas & $\mathbf{S}$ \\
\hline Chrysobalanaceae & 27 & Gesneriaceae & 9 & Vitaceae & 11 & Commelinaceae & 11 & Orchidaceae & 175 & Loranthaceae & 13 \\
\hline Rutaceae & 27 & Ericaceae & 8 & Polygalaceae & 10 & Iridaceae & 10 & Bromeliaceae & 68 & Balanophoraceae & 5 \\
\hline Asteraceae & 26 & Lamiaceae & 7 & Menispermaceae & 9 & Lentibulariaceae & 10 & Cactaceae & 22 & Viscaceae & 2 \\
\hline Moraceae & 26 & Malvaceae & 7 & Smilacaceae & 9 & Moraceae & 9 & Araceae & 20 & Apodanthaceae & 1 \\
\hline Monimiaceae & 25 & Onagraceae & 7 & Poaceae & 8 & Bromeliaceae & 8 & Gesneriaceae & 18 & Totais: 4 famílias & \\
\hline Bignoniaceae & 23 & Polygonaceae & 7 & Rubiaceae & 7 & Araceae & 7 & Piperaceae & 17 & 8 gêneros & \\
\hline Malvaceae & 23 & Verbenaceae & 7 & Dilleniaceae & 6 & Euphorbiaceae & 7 & Begoniaceae & 3 & 20 espécies & \\
\hline Salicaceae & 22 & Campanulaceae & 6 & Euphorbiaceae & 6 & Xyridaceae & 7 & Totais: 7 famílias & & & \\
\hline Sapindaceae & 22 & Scrophulariaceae & 6 & Amaranthaceae & 5 & Apiaceae & 6 & 86 gêneros & & & \\
\hline Meliaceae & 20 & Poaceae & 5 & Begoniaceae & 5 & & & 323 espécies & & & \\
\hline Totais: 84 famílias & & Totais: 40 famílias & & Totais: 36 famílias & & Totais: 59 famílias & & & & & \\
\hline 386 gêneros & & 174 gêneros & & 150 gêneros & & 209 gêneros & & & & & \\
\hline 1437 espécies & & 584 espécies & & 483 espécies & & 491 espécies & & & & & \\
\hline
\end{tabular}

climáticos $\mathrm{CwA}$ e $\mathrm{CwB}$, segundo a classificação de Köppen, sendo que, para quase todas as ACD, independentemente do hábito, os levantamentos apresentaram uma posição intermediária entre as localidades ombrófilas e semidecíduas. A presença de áreas aluviais, o relevo montanhoso na ReBio do Grama e as temperaturas mais amenas do Morro do Imperador podem representar fatores compensatórios à estacionalidade climática nessa região, enquanto a maior proximidade geográfica com as florestas ombrófilas pode facilitar o estabelecimento de populações de espécies típicas das florestas perenifólias, conforme constatado por Pifano et al. (2007).

Para alguns hábitos as $\mathrm{ACD}$ destacaram gradientes de substituição florística entre as formações ombrófila e estacional, enquanto outros sugeriram dicotomias mais evidentes entre as formações. Entretanto, os autovalores dos dois primeiros eixos das ACD foram significativos somente para espécies arbóreas e ervas saxícolas. Tanto para a flora completa como para arbustos e ervas terrícolas somente o primeiro eixo mostrouse significativo, enquanto que para as trepadeiras, epífitas, hemiepífitas e parasitas, os primeiros eixos não foram significativos. Esses resultados sugerem a ausência de relações lineares simples entre a ordenação das amostras e variações ambientais como a estacionalidade climática, esperada como um dos principais fatores distintivos entre as formações analisadas (Oliveira Filho \& Fontes 2000; Oliveira Filho et al. 2005). A distribuição 


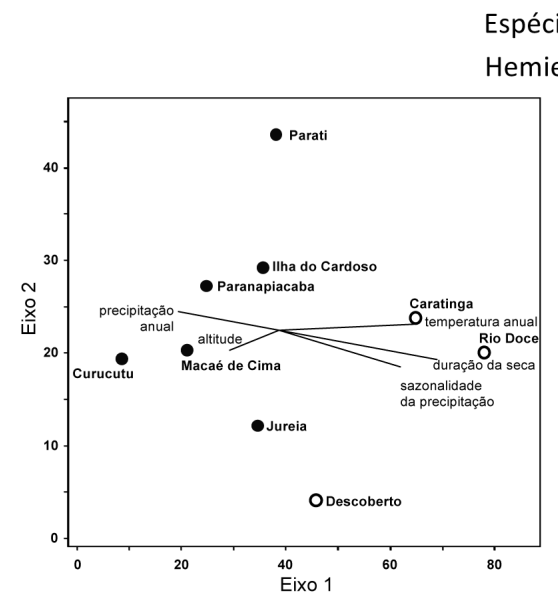

spécies hemiepifíticas

emiepiphytes species
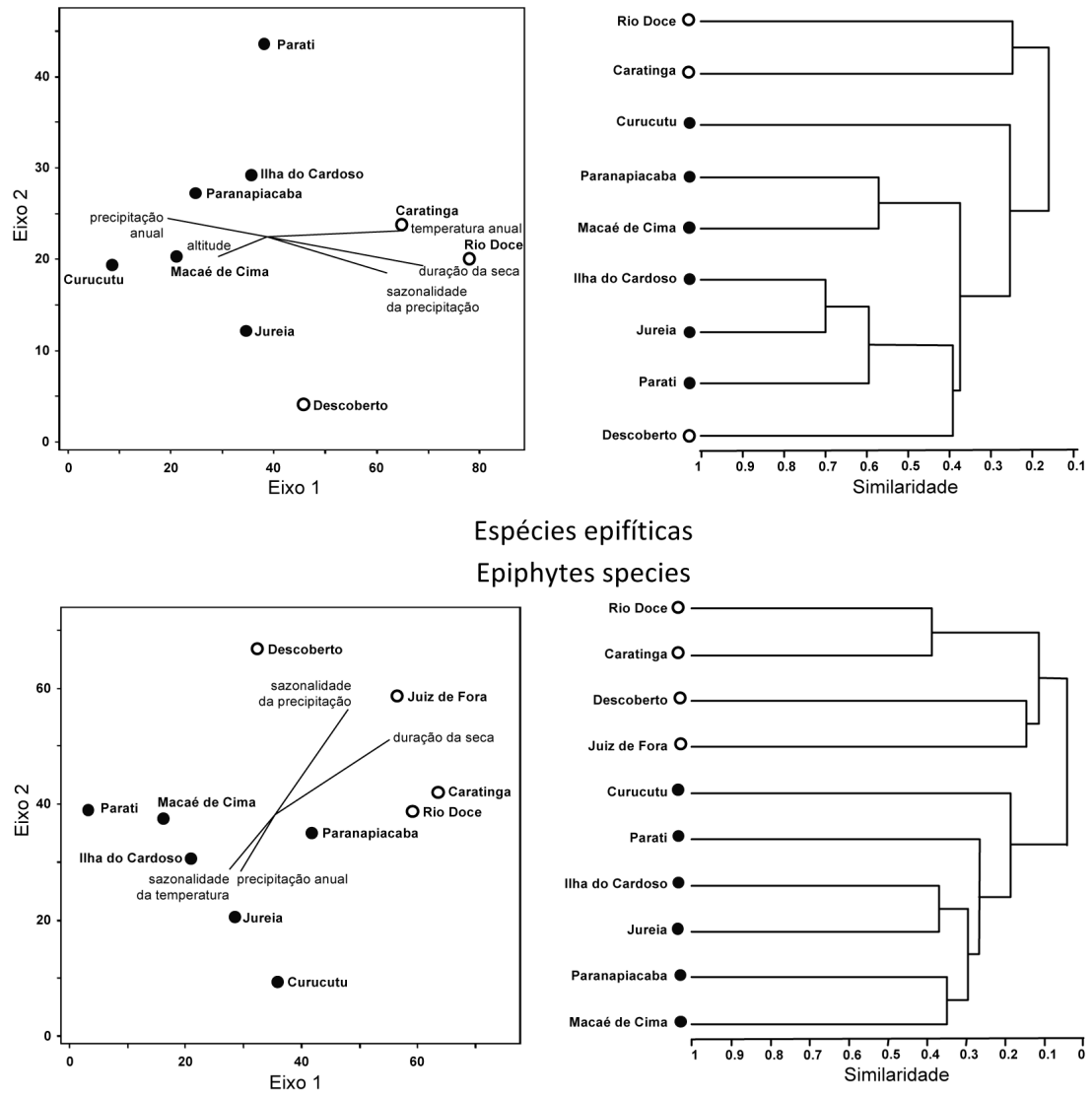

Espécies epifíticas

Epiphytes species

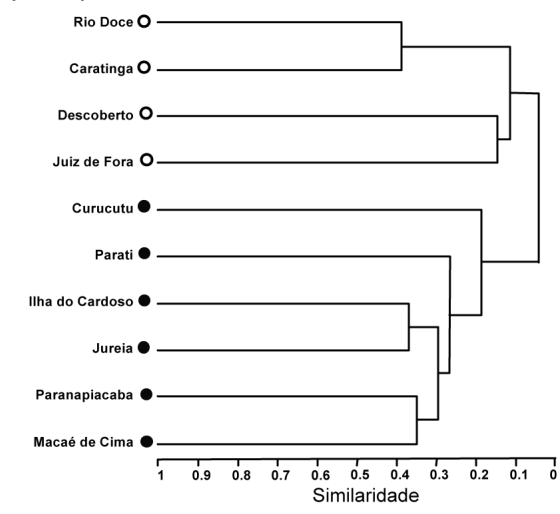

Espécies parasitas

Parasites species
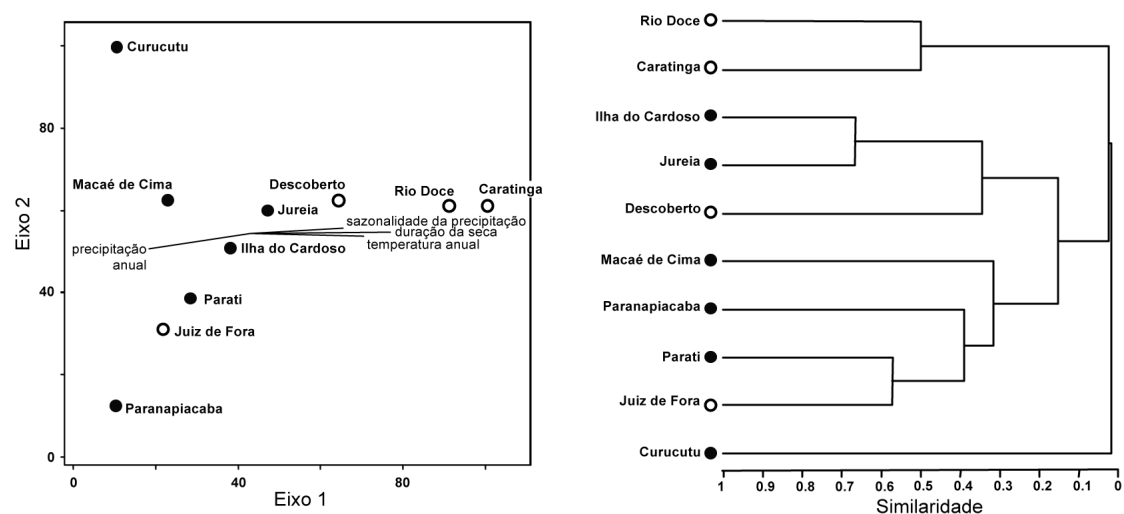

Figura 4 - Análises multivariadas das dez listagens florísticas mostrando, do lado esquerdo, a ordenação das localidades por análise de correspondência distendida (ACD) e, do lado direito, o dendrograma de classificação das mesmas áreas obtido por análise de agrupamento. (a) Espécies hemiepifíticas, (b) espécies epifíticas e (c) espécies parasitas. Círculos vazios e cheios são áreas onde predominam, respectivamente, florestas estacionais semideciduais e florestas ombrófilas densas.

Figure 4-Multivariate analyzes of the ten floristic lists showing the left side, the ordering of the locations for extended correspondence analysis (DCA) and the right, the dendrogram classification of the same areas obtained by cluster analysis. (a) hemiepiphytes species, (b) epiphytes species and (c) parasites species. Empty circles and full circles are areas dominated, respectively, semideciduous forests and tropical rainforests. 
Tabela 5 - Resumo das análises multivariadas da composição da flora de angiospermas de 10 áreas inventariadas no Sudeste do Brasil (vide Figs. 2 a 4). As análises foram realizadas para a flora completa e para as espécies organizadas por hábito. Para as análises de correspondência distendida (ACD) são fornecidos o autovalor e a respectiva significância nos três primeiros eixos de ordenação. Para as análises de correlação florística com as distâncias geográficas, são apresentados os testes de Mantel. Resultados significativos $(\mathrm{P}<0,05)$ estão evidenciados em negrito.

Table 5 - Summary of multivariate analyzes of angiosperm floristic composition of 10 areas surveyed in southeastern Brazil (see Figs. 2-4). The analyzes were performed for the complete flora and for species arranged in habits. For the detrend correspondence analysis (DCA) the eigen values and its significance in the first three ordination axes are provided. For the analysis of floristic correlation with geographic distances, Mantel tests are presented. Significant results $(\mathrm{P}<0.05)$ are highlighted in bold.

\begin{tabular}{lcccccccc}
\hline \multirow{2}{*}{$\begin{array}{c}\text { Formas de } \\
\text { vida }\end{array}$} & \multicolumn{2}{c}{ ACD - Eixo 1 } & \multicolumn{2}{c}{ ACD - Eixo 2 } & \multicolumn{2}{c}{ ACD - Eixo 3 } & \multicolumn{2}{c}{ Teste de Mantel } \\
\cline { 2 - 9 } & Autovalor & $\boldsymbol{P}$ & Autovalor & $\boldsymbol{P}$ & Autovalor & $\boldsymbol{P}$ & $\boldsymbol{R}$ & $\boldsymbol{P}$ \\
\hline Flora completa & 0,603 & $\mathbf{0 , 0 0 1}$ & 0,354 & 0,892 & 0,125 & 0,879 & 0,598 & $\mathbf{0 , 0 0 4}$ \\
Árvores & 0,507 & $\mathbf{0 , 0 0 1}$ & 0,336 & $\mathbf{0 , 0 0 2}$ & 0,197 & 0,316 & 0,534 & $\mathbf{0 , 0 0 4}$ \\
Arbustos & 0,754 & $\mathbf{0 , 0 0 1}$ & 0,435 & 0,952 & 0,289 & 0,502 & 0,568 & $\mathbf{0 , 0 0 2}$ \\
Trepadeiras & 0,462 & 0,969 & 0,487 & $\mathbf{0 , 0 3 9}$ & 0,290 & 0,320 & 0,578 & $\mathbf{0 , 0 0 3}$ \\
Ervas terrícolas & 0,683 & $\mathbf{0 , 0 0 1}$ & 0,375 & 0,988 & 0,051 & 0,994 & 0,534 & $\mathbf{0 , 0 0 2}$ \\
Ervas saxícolas & 0,771 & $\mathbf{0 , 0 3 8}$ & 0,585 & $\mathbf{0 , 0 2 8}$ & 0,256 & 0,305 & 0,159 & 0,131 \\
Epífitas & 0,465 & 0,987 & 0,234 & 1,000 & 0,124 & 0,910 & 0,458 & $\mathbf{0 , 0 0 6}$ \\
Hemiepífitas & 0,596 & 0,292 & 0,284 & 1,000 & 0,790 & 1,000 & 0,393 & $\mathbf{0 , 0 0 8}$ \\
Parasitas & 0,908 & 0,315 & 0,553 & 0,593 & 0,624 & 0,988 & 0,289 & $\mathbf{0 , 0 4 0}$ \\
\hline
\end{tabular}

geográfica dos levantamentos utilizados sugere uma coadunação de gradientes longitudinais, latitudinais e altitudinais afetando de diversos modos as relações florísticas entre os distintos hábitos. Entretanto as ordenações não significativas podem estar associadas a um baixo compartilhamento de espécies entre levantamentos ou a uma baixa riqueza de espécies de alguns hábitos, sugerindo um forte padrão geográfico que não pode ser explicado somente por aspectos climáticos.

Oliveira-Filho \& Fontes (2000) constataram que variações na sazonalidade e na precipitação total influenciam a distribuição tanto das espécies arbóreas quanto das formações florestais do Domínio Atlântico. De maneira geral, a dicotomia foi mais fortemente associada à duração da estação seca associada à sazonalidade da precipitação, com valores mais elevados de duração da estação seca nas áreas setentrionais, e precipitação anual e variações de temperatura, com valores mais elevados nas áreas meridionais. Em alguns casos, a temperatura anual surgiu como variável relevante aumentando na direção das áreas setentrionais. Como as áreas do primeiro grupo, que correspondem às florestas estacionais, estão todas ao norte das áreas do segundo grupo, que correspondem às florestas ombrófilas, os padrões observados possivelmente não estão vinculados somente ao caráter estacional ou ombrófilo desses tipos florestais, mas também a variações associadas à latitude e principalmente à altitude, que influenciam a temperatura (Huggett 1995; Oliveira-Filho et al. 2006). Corroborando, houve uma alta correlação da latitude tanto com os valores da estacionalidade na precipitação $(R=0,91$, $P<10^{-3}$ ) quanto da temperatura $\left(R=0,85, P<10^{-3}\right)$, não havendo como evidenciar os efeitos separadamente.

A ordenação das espécies arbóreas sugeriu um gradiente não muito abrupto de substituição florística entre as florestas ombrófilas e estacionais, devido à alta porcentagem de espécies compartilhadas (Tab. 3). Isto denota a existência de um conjunto de espécies arbóreas da floresta ombrófila que seriam tolerantes a uma estacionalidade climática mais definida e prolongada (Oliveira-Filho \& Fontes 2000; Scudeller et al. 2001). Variações climáticas associadas com o aumento da altitude destacaram na ordenação os levantamentos em áreas de maior altitude (Macaé de Cima, Curucutu e Paranapiacaba) e demostraram uma maior proximidade entre os levantamentos das áreas meridionais de menor altitude (Ilha do Cardoso, Juréia e Parati) com as florestas semidecíduas.

Uma forte correlação espacial foi observada para as espécies arbóreas entre formações semidecíduas dentro da mesma região geográfica. Os fragmentos no leste de Minas de Gerais apresentaram 206 espécies arbóreas exclusivas, enquanto os fragmentos ao sul da Zona da Mata apresentaram 
107 espécies, sendo que 88 compartilhadas entre as duas áreas. A presença de espécies arbóreas das florestas ombrófilas do Espírito Santo na composição florística das florestas semidecíduas da bacia do Rio Doce também contribui para a ocorrência de um gradiente latitudinal de substituição florística dentro das florestas estacionais, uma vez que as matas ciliares do Rio Doce e seus tributários funcionavam no passado como corredores naturais (Silva 2000; Rolim et al. 2006; Soares-Júnior 2008). Algumas espécies arbóreas raras como Tripterodendron filicifolium Radlk., Chrysophyllum imperiale (Linden ex K.Koch \& Fintelm.) Benth. \& Hook. e Paradrypetes ilicifolia Kuhlm. foram encontradas apenas no vale do Rio Doce dentre as áreas comparadas. Em contrapartida, muitas espécies arbóreas reconhecidas como "supertramp" (OliveiraFilho \& Fontes 2000) apareceram em todas as áreas semidecíduas como Tapirira obtusa, Xylopia sericea, Mabea fistulifera, Apuleia leiocarpa, Platypodium elegans, Vismia magnoliifolia, Psidium rufum e Cordiera elliptica.

Para o hábito arbustivo, a floresta ombrófila apresentou quase o dobro de espécies exclusivas em relação às florestas estacionais (Tab. 3). A influência altitudinal foi marcante no agrupamento deste hábito (Fig. 2). Macaé de Cima destacou-se dos demais levantamentos através de uma relação mais distante com as demais áreas de altitude como Curucutu e Paranapiacaba, que se aproximaram das florestas ombrófilas e estacionais na mesma faixa latitudinal. A alta dispersão nas ACD das áreas de altitude sugere a ausência de correspondência florística, entre o mesmo tipo florestal em altitudes similares e latitudes relativamente próximas na Floresta Atlântica, sugerindo a influência de fatores biogeográficos distintos entre essas regiões geográficas. A importância dos arbustos na composição e estrutura de florestas normalmente aumenta com a altitude, entretanto a riqueza de espécies arbustivas foi maior nas florestas ombrófilas de baixa altitude do que em florestas ombrófilas montanas (Oliveira-Filho \& Fontes 2000). Levantamentos quantitativos futuros poderão confirmar se, com o aumento na densidade, ocorre uma redução na riqueza para esse estrato ao longo de gradientes altitudinais.

A riqueza das trepadeiras apresentou-se similar entre os levantamentos de florestas semidecíduas e ombrófilas (Tab. 3). Entre as florestas ombrófilas novamente uma separação altitudinal foi verificada entre as faixas montanas e as terras baixas.
Cerca de $30 \%$ das trepadeiras foram restritas às florestas estacionais, similar ao encontrado com os arbustos (28\%) e ambos um pouco superiores àquilo observado para as arbóreas (27\%). Essas proporções sugerem uma considerável riqueza desses hábitos nas florestas estacionais, e destacam uma clara separação entre os principais tipos florestais analisados e uma forte estruturação geográfica. Apesar do caráter heliófito comum entre as trepadeiras, este hábito parece responder às diferentes condições climáticas entre as florestas ombrófilas e estacionais, com uma considerável riqueza específica e com regionalismos florísticos evidentes no Domínio da Floresta Atlântica (Clark \& Clark 1990; Gentry 1991). A ausência de autovalores significativos nas ordenações pode estar associada a uma maior dissimilaridade florística entre os levantamentos, evidenciando não somente um gradiente de substituição florística, como também a entrada de um número considerável de espécies exclusivas por região geográfica.

As ervas terrestres também apresentaram uma forte dicotomia entre as florestas estacionais e ombrófilas e somente $18 \%$ das espécies desta hábito foram compartilhadas entre as duas formações, porcentagem semelhante aos arbustos (Tab. 3). Apesar dos dendrogramas de ervas terrestres serem similares ao das árvores, trepadeiras e epífitas, uma relação distinta entre os levantamentos foi observada. Parati e Macaé de Cima se destacaram na análise de agrupamento, enquanto Curucutu destacou-se abruptamente na ACD. A destacada posição desta área pode se dever à presença de espécies sulinas nas partes mais elevadas do Planalto Atlântico Paulista (Meirelles et al. 2008). Poaceae, Cyperaceae e Orchidaceae foram as famílias mais ricas dentre as ervas nas 10 localidades (Tab. 4).

Dentre as espécies herbáceas ocorrentes nas florestas estacionais, 50 estiveram restritas à região leste da Zona da Mata de Minas Gerais, 33 ao sul e somente 11 foram compartilhadas. Estes resultados são similares aos observados para as trepadeiras, destacando novamente um gradiente latitudinal dentro das florestas estacionais, fato também justificado pela significativa diferença florística entre os estratos herbáceos das florestas do Vale do Rio Doce e da Zona da Mata sul (Lombardi \& Gonçalves 2000; Pifano et al. 2007). Um considerável padrão geográfico foi evidenciado para este hábito pela forte correlação espacial constatada pelo teste de Mantel. A separação 
latitudinal dentro das florestas ombrófilas de terras baixas e dentre as florestas estacionais sugerem regionalismos florísticos marcantes para esse hábito no Domínio Atlântico. Barreiras geográficas físicas e climáticas podem ser bem mais efetivas para a dispersão das espécies herbáceas, e em adição, seu ciclo de vida mais curto e sazonal, pode acentuar ainda mais os regionalismos florísticos (Citadini-Zanette et al. 2001; Roovers et al. 2004)

Para as ervas saxícolas, epífitas, hemiepífitas e parasitas um gradiente de substituição florística foi observado com uma forte discrepância na riqueza entre as florestas ombrófilas e estacionais. Vinte uma espécies parasitas foram observadas nos levantamentos das florestas ombrófilas e estacionais (Tabs. 2 e 3). Nas florestas ombrófilas foram observadas 13 espécies, duas nas florestas estacionais e seis comuns entre as formações (Tab. 3). Em todas as áreas observou-se uma baixa riqueza específica neste grupo, isto pode estar relacionado à dificuldade de localizar certas plantas parasitas ao longo das coletas (e.g. Balanophoraceae e Apodanthaceae).

As ervas saxícolas foram representadas nos dois tipos florestais por apenas quatro famílias (Tab. 2). Quatro espécies foram registradas somente nas florestas estacionais, enquanto outras 44 somente nas florestas ombrófilas e seis compartilhadas entre dois tipos florestais (Tab. 4). Destaca-se neste hábito as áreas de Macaé de Cima (27 spp.) e Paranapiacaba (21 spp.) com as maiores riquezas específicas. A riqueza de espécies por levantamento neste hábito esta limitada à ocorrência de afloramentos ou matacões, habitats bem mais raros e condicionados à geomorfologia local. Também vale destacar que este tipo de informação muitas vezes é omitida nas observações de coleta o que dificulta uma análise mais acurada deste hábito.

As famílias mais ricas entre as epífitas foram Orchidaceae (175 spp.), Bromeliaceae (68 spp.), Cactaceae (22 spp.) e Araceae (20 spp.) (Tab. 4). Estes altos valores em Araceae, Bromeliaceae e Orchidaceae reafirmam padrões globais (Madison 1977) neotropicais (Gentry \& Dodson 1987) e regionais (Menini Neto et al. 2009) na distribuição de epífitas nas famílias de angiospermas. A maior diversidade específica de Cactaceae em relação a Araceae, deve-se ao fato de que hemiepífitas foram analisadas separadamente no presente trabalho, diferentemente dos estudos supracitados. As epífitas da ReBio do Grama são predominantemente um subconjunto das espécies ocorrentes nas florestas ombrófilas. Das 41 espécies coletadas, sete foram exclusivas, três compartilhadas com as demais florestas estacionais, 24 com as florestas ombrófilas e sete ocorreram em ambas as formações. Neste hábito, uma riqueza discrepante entre as florestas ombrófilas (266 spp. exclusivas) e as florestas estacionais (14 spp. exclusivas) foi observada, com 31 espécies compartilhadas entre as duas formações (Tab. 3). A estacionalidade climática e a precipitação anual total parecem ser fortes limitantes para a riqueza e distribuição de espécies deste hábito na Floresta Atlântica (Gentry \& Dodson 1987).

$\mathrm{Na}$ ReBio do Grama foram coletadas 11 espécies hemiepífitas, com três exclusivas, quatro compartilhadas com as florestas ombrófilas e quatro com as florestas estacionais. Do total de espécies oito foram restritas às florestas estacionais, seis compartilhadas com as ombrófilas e 18 restritas às ombrófilas (Tab. 3). Dentre os hábitos analisados, epífitas e hemiepífitas apresentaram as mais baixas correlações com a distância geográfica. A maior similaridade entre as áreas de altitude (Paranapiacaba e Macaé de Cima) e entre florestas de terras baixas corroboram os resultados obtidos por Menini et al. (2009) para áreas do Sudeste e Sul do Brasil. Porém, são contrários aos encontrados por Leitman (2013) quando utilizando uma maior amplitude latitudinal e longitudinal.

Como conclusões tem-se que: a ReBio do Grama destacou-se com uma posição intermediária entre as florestas estacionais e as ombrófilas, com $43 \%$ de suas espécies ocorrendo nas duas formações, assim como o Morro do Imperador em Juiz de Fora. A área apresentou uma considerável porcentagem de espécies exclusivas (18,6\%), similar à compartilhada com as florestas estacionais $(19,4 \%)$ e com as ombrófilas $(18,8 \%)$. A menor riqueza observada na ReBio do Grama em relação às florestas ombrófilas, associada a uma maior riqueza de Fabaceae e Bignoniaceae e uma menor riqueza de Myrtaceae e Orchidaceae aproxima seu perfil florístico ao de florestas estacionais semidecíduas do sudeste brasileiro (Leitão-Filho, 1987; Oliveira-Filho \& Fontes 2000). As florestas ombrófilas apresentaram uma maior riqueza específica para todos os hábitos, entretanto para vários destes a contribuição de espécies exclusivas das florestas estacionais foi maior do que $25 \%$, denotando a importância dessas florestas para 
a riqueza total do Domínio Atlântico já que os resultados encontrados nas ACD demonstraram diferenças florísticas marcadas pela substituição de espécies de ervas, arbustos e trepadeiras entre as formações ombrófilas e semidecíduas.

Onúmero reduzido de espécies compartilhadas entre as áreas, associado à alta riqueza regionalizada de alguns hábitos são possíveis explicações para a baixa significância observada nas ACD para os hábitos de ciclo mais curto, uma vez que estas análises de ordenação trabalham com a posição espacial ocupada pela localidade em função de suas semelhanças florísticas (Kent \& Cooker 1992). Isto também demonstra a importância da conservação de fragmentos nas diferentes regiões geográficas da Floresta Atlântica como estratégia para a conservação de sua diversidade total.

Prance et al. (2000) relataram o alto grau de endemismo de alguns grupos na Floresta Atlântica, destacando que coletas realizadas em seus remanescentes continuam a trazer novas espécies e também casos de distribuições disjuntas. Os resultados obtidos neste trabalho demonstram a importância de levantamentos florísticos completos como uma das principais fontes de informações, sejam elas a descoberta de novas espécies ou registro de espécies raras, redescoberta de espécies presumidas como extintas ou mesmo novos registros de ocorrências. Também reforçam que somente através de inventários completos é possível refletir sobre a diversidade total de uma área, fornecendo informações preciosas para a conservação da flora brasileira.

\section{Agradecimentos}

À COPASA o financiamento na etapa inicial do projeto de levantamento florístico da ReBio. À FAPEMIG e ao CNPq as bolsas e auxílios concedidos. A Daniela Zappi e dois revisores anônimos a leitura crítica e diversas sugestões. Ao Sr. Luiz, responsável pela ReBio, o apoio em campo e por ter hospedado durante anos toda a equipe em sua casa.

\section{Referências}

Almeida, D.S. 2000. Recuperação da Mata Atlântica. Editus, Ilhéus. 130p.

Almeida, V.R.; Temponi, L.G. \& Forzza R.C. 2005. Araceae da Reserva Biológica da Represa do Grama, Descoberto, MG. Rodriguésia 56: 127- 144.

APG [Angiosperm Phyllogeny Group] III. 2009. An update of the Angiosperm Phylogeny Group classification for the orders and families of flowering plants. Botanical Journal of the Linnean Society 141: 399-436.

Araújo, F.S. 1998. Estudos fitogeográficos do carrasco no nordeste do Brasil. Tese de Doutorado. Universidade Estadual de Campinas, Campinas. 97p.

Assis, L.C.S.; Forzza, R.C. \& Werff, H.V.D. 2005. A família Lauraceae na Reserva Biológica da Represa do Grama, Minas Gerais, Brasil. Boletim de Botânica Universidade de São Paulo 23: 113-139.

Assumpção, J. \& Nascimento, M.T. 2000. Estrutura e composição florística de quatro formações vegetais de Restinga no complexo lagunar Grussaí/Iquipari, São João da Barra, RJ, Brasil. Acta Botânica Brasílica 14: 301-315.

Barros, F.; Melo, M.M.R.F.; Chiea, S.A.C.; Kirizawa, M.; Wanderley, M.G.L. \& Jung-Mendaçolli, S.L. 1991. Caracterização geral da vegetação e listagem das espécies ocorrentes. In: Melo, M.M.R.F.; Barros, F.; Wanderley, M.G.L.; Kirizawa, M.; Jung-Mendaçolli, S.L. \& Chiea, S.A.C. (eds.). Flora fanerogâmica da Ilha do Cardoso. Vol. 1. Instituto de Botânica, São Paulo. Pp. 1-184.

Clark, D.B. \& Clark, D.A. 1990. Distribution and effects on tree growth of lianas and woody hemiepiphytes in a Costa Rican tropical wet forest. Journal of Tropical Ecology 6: 321-331.

Citadini-Zanette, V.; Santos, R. \& Sobral, M. 2001. Levantamento florístico da vegetação arbustivaarbórea em área ecotonal entre Restinga e Floresta Ombrófila Densa de Terras Baixas (Praia de Palmas, Governador Celso Ramos, Santa Catarina, Brasil). Revista Tecnologia e Ambiente 7: 105-120.

Dittrich, V.A.O.; Waechter, J.L. \& Salino, A. 2005. Species richness of pteridophytes in a montane Atlantic rain forest plot of Southern Brazil. Acta Botanica Brasilica 19: 519-525.

Embrapa 2003. Brasil visto do espaço. Disponível em $<$ http://www.cdbrasil.cnpm.embrapa.br $>$. Acesso em 23 Out 2011.

Farinazzo, N.M. \& Salimena, F.R.G. 2007. Passifloraceae na Reserva Biológica da Represa do Grama, Descoberto, Minas Gerais, Brasil. Rodriguésia 58: 823-833.

Felfili, J.M.; Carvalho, F.A.; Libano, A.M.; Venturoli, B.A.S.P. \& Machado, E.L.M. 2011. Análise multivariada: princípios e métodos em estudos de vegetação. In: Felfili, J.M.; Eisenlohr, P.V.; Melo, M.M.R.F.; Andrade L.A. \& Meira Neto, J.A.A. (eds.). Fitossociologia no Brasil: métodos e estudos de casos. Vol. 1. Ed. UFV, Viçosa. 558p.

Fernandes, A. 2003. Conexões florísticas do Brasil. Banco do Nordeste, Fortaleza. 134p.

Figueiredo, J.B. \& Salino, A. 2005. Pteridófitas de quatro reservas particulares do patrimônio natural ao sul 
da região metropolitana de Belo Horizonte, Minas Gerais, Brasil. Lundiana 6: 83-94.

Fraga, C.N. \& Aymard, A.G.C. 2007. Tetracera forzzae (Dilleniaceae), uma nova espécie para a Zona da Mata de Minas Gerais, Brasil. Novon 17: 433- 435.

Forzza, R.C.; Baumgratz, J.F.A.; Bicudo, C.E.M.; Carvalho Jr., A.A.; Costa, A.; Costa, D.P.; Hopkins, M.; Leitman, P.M.; Lohmann, L.G.; Maia, L.C.; Martinelli, G.; Menezes, M.; Morim, M.P.; Coelho, M.A.N.; Peixoto, A.L.; Pirani, J.R.; Prado, J.; Queiroz, L.P.; Souza, V.C.; Stehmann, J.R.; Sylvestre, L.S.; Walter, B.M.T. \& Zappi, D. (eds.). 2010. Catálogo de plantas e fungos do Brasil. Vols. I-II. Jardim Botânico do Rio de Janeiro, Rio de Janeiro. Xp.

Garcia, R.J.F. \& Pirani, J.R. 2005. Análise florística, ecológica e fitogeográfica do Núcleo Curucutu, Parque Estadual Serra do Mar (São Paulo, SP), com ênfase nos campos junto à crista da Serra do Mar. Hoehnea 32: 1-48.

Gentry, A.H. 1990. Floristic similarities and differences between Southern Central America and upper and Central Amazonia. In: Gentry, A.H. (ed.). Four Neotropical rain forests. Yale University Press, London. Pp. 141-160.

Gentry, A.H. 1991. The distribution and evolution of climbing plants. In: Putz, F.E. \& Mooney, H.A. (eds.). The biology of vines. Cambridge University Press, Cambridge. Pp. 3-49.

Gentry, A.H. \& Dodson, C.H. 1987. Diversity and biogeography of neotropical vascular epiphytes. Annals of the Missouri Botanical Garden 74: 205-233.

Hammer, Ø.; Harper, D.A.T \& Ryan, P.D. 2001. Paleontological statistics software package for education and data analysis. Palaeontologia Electronica 4: 1-9.

Heringer, E.P. 1947. Contribuição ao conhecimento da flora da Zona da Mata de Minas Gerais. Boletim do Serviço Nacional de Pesquisas Agronômicas, Rio de Janeiro 2: 1-187.

Hugget, R.J. 1995. Geoecology, an evolutionary approach. Routledge Inc., London. 320p.

Kirizawa, M.; Sugiyama, M.; Lopes, E.A. \& Custodio Filho, A. 2003. Flora fanerogâmica da Reserva Biológica do Alto da Serra de Paranapiacaba. Disponível em <http://www.ibot.sp.gov.br/ PESQUISA/paranapiacaba/paranapiacaba.htm>. Acesso em 15 Fev 2012.

Kramer, K.U. \& Green, P.S. 1990. The families and genera of vascular plants. Vol. 1. Pteridophytes and gymnosperms. Springer-Verlag, Berlin. 404p.

Leitão-Filho, H.F. 1987. Considerações sobre a florística de florestas tropicais e sub-tropicais do Brasil. Instituto de Pesquisa de Estudos Florestais 35: 41-46.

Lima, H.C. \& Guedes-Bruni, R.R. (orgs.). 1997. Serra de Macaé de Cima: diversidade florística e conservação em Mata Atlântica. Jardim Botânico do Rio de Janeiro, Rio de Janeiro. 346p.

Lino, C.F. 2009. Texto síntese: a mata atlântica. Portal da Reserva da Biosfera da Mata Atlântica: anuário Mata Atlântica. Conselho Nacional Reserva da Biosfera da Mata Atlântica, São Paulo. Disponível em < http://www.rbma.org.br/anuario/mata_01_ sintese.asp>. Acesso em 6 Fev 2012.

Leitman, P.M. 2013. Angiospermas epífitas de um remanescente de floresta montana no sul da Bahia, Brasil. Dissertação de Mestrado. Jardim Botânico do Rio de Janeiro. 51p.

Lista de Espécies da Flora do Brasil. 2012. Jardim Botânico do Rio de Janeiro. Disponível em $<$ http:// floradobrasil.jbrj.gov.br/2012>. Acesso em 31 Jun 2012.

Lobão, A.Q.; Forzza R.C. \& Mello-Silva, R. 2006. Annonaceae da Reserva Biológica da Represa do Grama, Descoberto, MG, com uma nova espécie. Rodriguésia 57: 137-147.

Lombardi, J.A. \& Goncalves, M. 2000. Composição florística de dois remanescentes de Mata Atlântica do sudeste de Minas Gerais, Brasil. Revista Brasileira de Botânica 23: 255-282.

Madison, M. 1977. Vascular epiphytes: their systematic occurrence and salient features. Selbyana 2: 1-13.

Mamede, M.C.H.; Cordeiro, I. \& Rossi, L. Flora vascular da Serra da Juréia, município de Iguape, São Paulo, Brasil. 2001. Boletim do Instituto de Botânica 15: 63-124.

Marques, M.C.M. 1997. Mapeamento da cobertura vegetal e listagem das espécies ocorrentes na Área de Proteção Ambiental de Cairuçu, Parati, RJ. Série Estudos e Contribuições n. 13. Jardim Botânico do Rio de Janeiro, Rio de Janeiro. Pp. 1-96.

Matozinhos, C.N. \& Konno, T.U.P. 2008. Apocynaceae s.l. na Reserva Biológica da Represa do Grama, Descoberto, Minas Gerais, Brasil. Rodriguésia 59: 87-98.

Mccune, B. \& Mefford, M.J. 2011. PC-ORD. Multivariate analysis of ecological data.Version 6.0. MjM Software, Gleneden Beach.

Meira-Neto, J.A.A.; Sousa, A.L.; Silva, A.F. \&. Paula, A. 1997. Estrutura de uma floresta estacional semidecidual submontana em área diretamente afetada pela Usina Hidrelétrica de Pilar, Ponte Nova, Zona da Mata de Minas Gerais. Revista Árvore 21: 337-344.

Meira-Neto, J.A.A. \& Martins, F.R. 2002. Composição florística de uma floresta estacional semidecidualmontana no município de Viçosa-MG. Revista Árvore 26: 437-446.

Meireles, L.D.; Shepherd, G.J. \& Kinoshita, L.S. 2008. Variações na composição florística e na estrutura fitossociológica de uma floresta ombrófila densa 
alto-montana na Serra da Mantiqueira, Monte Verde, MG. Revista Brasileira de Botânica 31: 559-574.

Melo, L.C.N. \& Salino, A. 2002. Pteridófitas de duas áreas de floresta da bacia do Rio Doce no estado de Minas Gerais, Brasil. Lundiana 3: 129-139.

Melo, L.C.N. \& Salino, A. 2007. Pteridófitas em fragmentos florestais da APA Fernão Dias, Minas Gerais, Brasil. Rodriguésia 58: 207-220.

Menini Neto, L.; Almeida, V.R. \& Forzza, R.C. 2004. A família Orchidaceae na Reserva Biológica da Represa do Grama - Descoberto, MG. Rodriguésia 55: 137-156.

Menini Neto, L., Forzza, R.C. \& Zappi, D. 2009. Angiosperm epiphytes as conservation indicators in forest fragments: a case study from southeastern Minas Gerais, Brazil. Biodiversity and Conservation 18: 3785-3807.

Mori, S.A.; Boom, B.M. \& Prance, G.T. 1981. Distrubuition patterns and conservation of eastern Brazilian coastal forest species. Brittonia 33:233-245

Murray-Smith, C.; Brummitt, N.A.; Oliveira-Filho, A.T.; Bachman, S.; Moat, J.; Lughadha, E.M.N. \& Lucas, E.J. 2008. Plant diversity hotspots in the Atlantic coastal forests of Brazil. Conservation Biology 23: 151-163.

Oliveira-Filho, A.T. 1993. Gradient analysis of an area of coastal vegetation in the state of Paraíba, Northeastern Brazil. Edinburgh Journal of Botany 50: 217-236.

Oliveira-Filho, A.T. 2009. Classificação das fitofisionomias da América do Sul cisandina tropical e subtropical: proposta de um novo sistema - prático e flexível - ou uma injeção a mais de caos? Rodriguésia 60: 237-258.

Oliveira-Filho, A.T.; Almeida, R.J.; Mello, J.M. \& Gavilanes, M.L. 1994a. Estrutura fitossociológica e variáveis ambientais em um trecho da mata ciliar do córrego dos Vilas Boas, Reserva Biológica do Poço Bonito, Lavras (MG). Revista Brasileira de Botânica 17: 67-85.

Oliveira-Filho, A.T.; Vilela, E.A.; Gavilanes, M.L. \& Carvalho, D.A. 1994b. Comparison of the woody flora and soils of six areas of montane semideciduous forest in Southern Minas Gerais, Brazil. Edinburgh Journal of Botany 51: 355-389.

Oliveira-Filho, A.T. \& Ratter, J.A. 1995. A study of the origin of central Brazilian forests by the analysis of plants species distribution patterns. Edinburgh Journal of Botany 52: 141-194.

Oliveira-Filho, A.T. \& Fontes, M.A.L. 2000. Patterns of floristic differentiation among Atlantic Forest in South-Eastern Brazil and the influence of climate. Biotropica 32(suppl.): 1-16.

Oliveira-Filho, A.T.; Tameirão Neto, E.; Carvalho, W.A.C.; Brina, A.E.; Werneck, M.; Vidal, C. \& Rezende, S. 2005. Análise florística do compartimento arbóreo de áreas de Floresta Atlântica sensu lato na região das Bacias do Leste (Bahia, Minas Gerais, Espírito Santo e Rio de Janeiro). Rodriguésia 56: 185-235.

Oliveira-Filho, A.T.; Jarenkow, J.A. \& Rodal, M.J.N. 2006. Floristic relationships of seasonally dry forests of eastern South America based on tree species distribution patterns. In: R.T. Pennington, J.A. Ratter \&G.P. Lewis (eds.). Neotropical savannas and dry forests: Plant diversity, biogeography and conservation. CRC Press, Boca Raton. Pp. 159-192.

Pifano, D.S.; Valente, A.S.M., Castro, R.M.; Pivari, M.O.D.; Salimena, F.R.G. \& Oliveira-Filho, A.T. 2007. Similaridade entre as fisionomias da vegetação do Morro do Imperador, Juiz de Fora, MG, com base na composição de sua flora fanerogâmica. Rodriguésia 58: 885-904.

Pereira, J.A.A.; Oliveira-Filho, A.T. \& Lemos Filho, J.P. 2007. Environmental heterogeneity and disturbance by humans control much of the tree species diversity of fragments of tropical montane seasonal forests in SE Brazil. Biodiversity and Conservation 16: 1761-1784.

Pivari, M.O.D. \& Forzza, R.C. 2005. A família Palmae na Reserva Biológica da Represa do Grama, Descoberto, MG. Rodriguésia 55: 115-124.

Prance, G. T.; Beentje, H.; Dransfield, J. \& Johns, R. 2000. The tropical flora remains undercolletted. Annals of Missouri Botanical Garden 87: 67-71.

Ribeiro M.C.; Metzger J.P.; Martensen A.C.; Ponzoni F.J. \& Hirota M.M. 2009.The Brazilian Atlantic Forest: How much is left, and how is the remaining forest distributed? Implications for conservation. Biological Conservation 142: 1141-1153.

Rolim, S.G.; Ivanauskas, N.M.; Rodrigues, R.R.; Nascimento, M.T.; Gomes, J.M.L.; Folli, D.A. \& Couto, H.T.Z. 2006. Composição Florística do estrato arbóreo da floresta estacional semidecidual na planície aluvial do Rio Doce, Linhares, ES, Brasil. Acta Botanica Brasilica 20: 549-561.

Roovers, P.; Baeten, S. \& Hermy, M. 2004. Plant species across path ecotones in a variety of common vegetation types. Plant ecology 170: 107-119.

Rothfels, C.J.; Sundue, M.A.; Larsson, Li-Y.K.A.; Kato, M.; Schuettpelz, E. \& Pryer, K.M. 2012. A revised family-level classification for eupolypod II ferns (Polypodiidae: Polypodiales). Taxon 61: 515-533.

Salis, S.M.; Shepherd, G.J. \& Joly, C.A. 1995. Floristic comparison of mesophytic semideciduous forest of the interior of the state of São Paulo, Southeast Brazil. Vegetatio 119: 155-164.

Scolforo, J. R. \& Carvalho, L.M. 2008. Zoneamento ecológico-econômico do estado de Minas Gerais. UFLA, Lavras. 161p.

Scudeller, V.V. 2002. Análise fitogeográfica da Mata Atlântica - Brasil. Tese de Doutorado. Universidade Estadual de Campinas, Campinas. 
Scudeller, V.V.; Martins, F.R. \& Shepherd, G.J. 2001. Distribution and abundance of arboreal species in the Atlantic Ombrophilous Dense Forest in Southeastern Brazil. Plant Ecology 152: 185-199.

Silva, A.F. \& Shepherd, G.J. 1986. Comparações florísticas entre algumas matas brasileiras utilizando análise de agrupamento. Revista Brasileira de Botânica 9: 81-86.

Silva, A.F. 2000. Floresta Atlântica. In: Mendonça, M.P. \& Lins, L.V. (eds.). Lista vermelha das espécies ameaçadas de extinção da flora de Minas Gerais. Belo Horizonte, Fundação Biodiversitas. Pp. 45-54.

Sylvestre, L. S. 1997. Pteridófitas da Reserva Ecológica de Macaé de Cima. In: Lima, H.C. \& Guedes-Bruni, R. (orgs.). Serra de Macaé de Cima: diversidade florística e conservação em Mata Atlântica. Rio de Janeiro: Jardim Botânico do Rio de Janeiro. Pp. 41-52.

Smith, A.R.; Pryer, K.M.; Schuettpelz, E.; Korall, P.; Schneider, H. \& Wolf, P.G. 2006. A classification for extant ferns. Taxon 55: 705-731.

Soares-Júnior, F.J. 2009. Estrutura da vegetação em um fragmento de floresta estacional semidecidual no distrito de Silvestre. Blucher, São Paulo. 90p.

Sobral, M. \& Couto, F. 2006. Four New Myrtaceae from Eastern Brazil. Novon 16: 520-529.

Sobral, M.; Grippa, C.R.; Souza, M.C.; Aguiar, O.T.; Bertoncello, R. \& Guimarães, T.B. 2012. Fourteen new species and two taxonomic notes on Brazilian Myrtaceae. Phytotaxa 50: 19-50.

Sobral, M. \& Stehmann, J.R. 2009. An analysis of new angiosperm species discoveries in Brazil (19902006). Taxon 58: 227-232.

Sommer, G. \& Ferrucci, S.M. 2004. A new species of Cupania sect. Trigonocarpus (Sapindaceae) from
Brazil. Botanical Journal of the Linnean Society146: 2017-221.

Stehmann, J.R.; Forzza, R.C.; Sobral, M. \& Kamino, L.H.Y. 2009. Gimnospermas e angiospermas In: Stehmann, J.R.; Forzza, R.C.; Salino, A.; Sobral, M.; Costa, D.P. \& Kamino, L.H.Y. (eds.). Plantas da Floresta Atlântica. Jardim Botânico do Rio de Janeiro, Rio de Janeiro. Pp. 27-37.

Tabarelli, M.; Pinto, L.P.; Silva, J.M.C.; Hirota, M. \& Bedê, L. 2005. Challenges and opportunities for biodiversity conservation in the Brazilian Atlantic forest. Conservation Biology 19: 695-700.

Tinôco, A.M.P.; Azevedo, I.C.A.D.; Marques, E.A.G; Mounteer, A.H.; Martins C.P.; Nascentes R. \& Reis, E.L. 2010. Avaliação de contaminação por mercúrio em Descoberto, MG. Engenharia Sanitária e Ambiental 15: 305-314.

Torres, R.B.; Martins, F.R. \& Kinoshita, L.S. 1997. Climate, soil and tree flora relationships in florests in the state of São Paulo, Southeastern Brazil. Revista Brasileira de Botânica 20: 41-49.

Veloso, H.P.; Rangel Filho, A.L.R. \& Lima, J.C. A. 1991. Classificação da vegetação brasileira adaptada a um sistema universal. Instituto Brasileiro de Geografia e Estatística (IBGE), Rio de Janeiro. 117p.

Versieux, L. M. \& Wendt, T. 2006. Checklist of the Bromeliaceae of Minas Gerais, Brazil, with notes on taxonomy and endemism. Selbyana 27: 107-146.

Walter, H. 1986. Vegetação e zonas climáticas: tratado de ecologia global. EPU, São Paulo. 326p.

Werneck, M.; Sobral, M.; Rocha, C.T.V.; Laundau, E.C. \& Stehmann, J.R. 2011. Distribution and endemism of angiosperms in the Atlantic Forest. Natureza \& Conservação 9:188-193.

Whitmore, T.C. 1990. An introduction to the tropical rain forests. Clarendon Press, Oxford. 226p. 


\section{Flora vascular da Reserva Biológica da Represa do Grama, Minas Gerais, e sua relação florística com outras florestas do sudeste brasileiro}

Vascular flora of the Reserva Biológica da Represa do Grama, Minas Gerais, and its floristic relationships with other forests from Southeastern Brazil

Rafaela Campostrini Forzza, Daniel Salgado Pifano, Ary Teixeira de Oliveira-Filho, Leonardo Dias Meireles, Patrícia Lobo Faria, Fátima Regina Salimena, Claudine M. Mynssen \& Jefferson Prado

Apêndice 1 - Lista das espécies de samambaias e licófitas registradas na REBIO do Grama, Descoberto, Minas Gerais. Appendix 1 - Check-list of fern and lycophyte species registered in the REBIO of Grama, Descoberto, Minas Gerais.

\begin{tabular}{|c|c|}
\hline Família / Espécie & Material testemunho \\
\hline \multicolumn{2}{|l|}{ ATHYRIACEAE } \\
\hline Diplazium cristatum (Desr.) Alston & Castro 427 \\
\hline Diplazium mutilum Kunze & Castro 619; Mynssen 739 \\
\hline \multicolumn{2}{|l|}{ ANEMIACEAE } \\
\hline Anemia mandioccana Raddi & Assis 479; Jascone 449 \\
\hline Anemia phyllitidis (L.) Sw. & Castro 281; Jascone 451 \\
\hline Anemia raddiana Link. & Jascone 417 \\
\hline Anemia villosa Willd. & Jascone 450 \\
\hline \multicolumn{2}{|l|}{ ASPLENIACEAE } \\
\hline Asplenium kunzeanum Klotzsch ex Rosenst. & Castro 70; Jascone 446 \\
\hline Asplenium mucronatum C. Presl & Castro 142, 615; Mynssen 738 \\
\hline $\begin{array}{l}\text { Hymenasplenium triquetrum (N. Murak. \& R.C. Moran) L. Regalado } \\
\text { \& Prada }\end{array}$ & Mynssen 734 \\
\hline \multicolumn{2}{|l|}{ BLECHNACEAE } \\
\hline Blechnum austrobrasilianum de la Sota & Mynssen 735 \\
\hline Blechnum brasiliense Desv. & Jascone 427 \\
\hline Blechnum occidentale $\mathrm{L}$. & Jascone 422; Mynssen 758 \\
\hline Salpichlaena volubilis (Kaulf.) J. Sm. & Mynssen 756 \\
\hline \multicolumn{2}{|l|}{ CYATHEACEAE } \\
\hline Alsophila setosa Kaulf. & Mynssen 742 \\
\hline Cyathea corcovadensis Domin & Castro 493; Jascone 437 \\
\hline Cyathea leucofolis Domin & Castro 408; Forzza 1728; Jascone 438 \\
\hline Cyathea phalerata Mart. & Jascone 439 \\
\hline \multicolumn{2}{|l|}{ DENNSTAEDTIACEAE } \\
\hline Dennstaedtia globulifera (Poir.) Hieron. & Augustin s.n. (CESJ 35078); Mynssen 732, 733 \\
\hline \multicolumn{2}{|l|}{ DRYOPTERIDACEAE } \\
\hline Ctenitis distans (Brack.) Ching & Jascone 434 \\
\hline Didymochlaena truncatula (Sw.) J. Sm. & Castro 622; Forzza 1755 \\
\hline Mickelia guianensis (Aubl.) R.C. Moran et al. & Mynssen 750 \\
\hline
\end{tabular}




\begin{tabular}{|c|c|}
\hline Família / Espécie & Material testemunho \\
\hline Olfersia cervina (L.) Kunze & Forzza 1754 \\
\hline Polybotrya speciosa Schott & Jascone 442; Mynssen 727, 737 \\
\hline \multicolumn{2}{|l|}{ HYMENOPHYLLACEAE } \\
\hline Abrodictyum rigidum (Sw.) Ebihara \& Dubuisson & Castro 71; Jascone 441 \\
\hline Polyphlebium angustatum (Carmich.) Ebihara \& Dubuisson & Mynssen 740 \\
\hline Trichomanes polypodioides $\mathrm{L}$. & Castro 244 \\
\hline Vandenboschia rupestris (Raddi) Ebihara \& K. Iwats. & Jascone 448 \\
\hline \multicolumn{2}{|l|}{ LINDSAEACEAE } \\
\hline Lindsaea arcuata Kunze & Jascone 423 \\
\hline Lindsaea lancea (L.) Bedd. & Castro 230; Mynssen 726 \\
\hline \multicolumn{2}{|l|}{ LOMARIOPSIDACEAE } \\
\hline Lomariopsis marginata (Schrad.) Kuhn & Mynssen 759 \\
\hline Nephrolepis exaltata (L.) Schott & Forzza 2100 \\
\hline \multicolumn{2}{|l|}{ LYGODIACEAE } \\
\hline Lygodium volubile Sw. & Jascone 418 \\
\hline \multicolumn{2}{|l|}{ MARATTIACEAE } \\
\hline Danaea moritziana C. Presl & Mynssen 757 \\
\hline Eupodium kaulfussii (J.Sm.) J.Sm. & Castro 621 \\
\hline \multicolumn{2}{|l|}{ POLYPODIACEAE } \\
\hline Campyloneurum decurrens (Raddi) C. Presl & Augustin s.n. (CESJ 35077); Castro 620 \\
\hline Campyloneurum lapathifolium (Poir.) Ching & $\begin{array}{l}\text { Castro 143, 553, 646; Forzza 1693, 1722, 1756; Mynssen } \\
736,749,752 ; \text { Jascone } 428\end{array}$ \\
\hline Campyloneurum nitidum C. Presl & Forzza 2098; Jascone 431 \\
\hline Dicranoglossum furcatum (L.) J. Sm. & Castro 518; Forzza 1723; Jascone 443 \\
\hline Microgramma squamulosa (Kaulf.) de la Sota & Jascone 433 \\
\hline Pecluma plumula (Willd.) M.G. Price & Castro 428 \\
\hline Pecluma robusta (Fée) M. Kessler \& A.R. Sm. & Forzza 1886; Mynssen 729, 751 \\
\hline Pecluma sicca (Lindm.) M.G. Price & Faria s.n. (CESJ 34483) \\
\hline Pecluma truncorum (Lindm.) M.G. Price & Mynssen 741 \\
\hline Pleopeltis astrolepis (Liebm.) E. Fourn. & Mynssen 746 \\
\hline Phlebodium aureum (L.) J. Sm. & Forzza 2031 \\
\hline Serpocaulon fraxinifolium (Jacq.) A.R. Sm. & Jascone 440 \\
\hline Serpocaulon triseriale (Sw.) A.R. Sm. & Castro 243; Lopes 33 \\
\hline \multicolumn{2}{|l|}{ PTERIDACEAE } \\
\hline Adiantopsis chlorophylla (Sw.) Fée & Jascone 419 \\
\hline Adiantum abscissum Schrad. & Jascone 435; Mynssen 754 \\
\hline Doryopteris varians (Raddi) J. Sm. & Forzza 2095; Jascone 424 \\
\hline Pteris brasiliense Raddi & Jascone \\
\hline Pteris decurrens C.Presl & Jascone 444 \\
\hline Pteris denticulata $\mathrm{Sw}$. & Jascone 429,430 \\
\hline Pteris splendens Kaulf. & Jascone 432, Mynssen 755 \\
\hline
\end{tabular}


Família / Espécie

\section{SELAGINELLACEAE}

Selaginella muscosa Spring

Selaginella suavis (Spring) Spring

Selaginella sulcata (Desv.) Spring

\section{TECTARIACEAE}

Tectaria incisa Cav.

\section{THELYPTERIDACEAE}

Thelypteris decussata (L.) Proctor

Thelypteris hispidula (Decne.) C. F. Reed

Thelypteris leprieurii (Hook.) R. M. Tryon

Thelypteris opposita (Vahl.) Ching

Thelypteris polypodioides (Raddi) C. F. Reed

Thelypteris rivularioides (Fée) Abbiatti
Material testemunho

Jascone 436

Castro 270

Castro 686

Assis 500

Mynssen 730

Jascone 420

Jascone 426

Jascone 425

Jascone 445; Mynssen 753

Jascone 421 
Apêndice 2 - Lista das espécies de angiospermas registradas na REBIO do Grama, Descoberto, Minas Gerais. *Espécies não registradas em Minas Gerais de acordo com Forzza et al. (2010). Nomes abaixo de cada família se referem aos especialistas que identificaram as amostras.

Appendix 2 - Check-list of the angiosperm species registered in the REBIO of Grama, Descoberto, Minas Gerais. *Species not recorded in Minas Gerais according to Forzza et al. (2010).

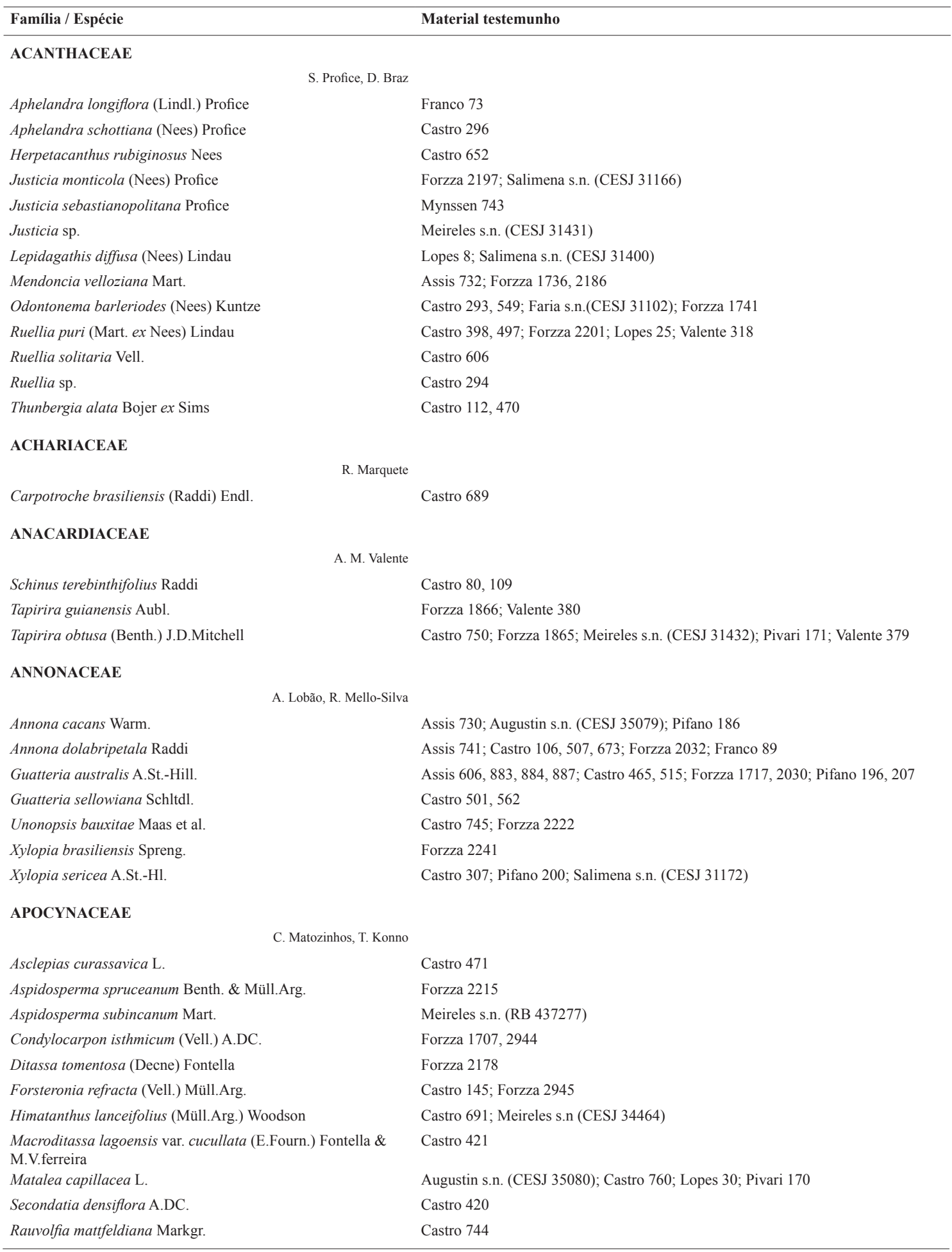




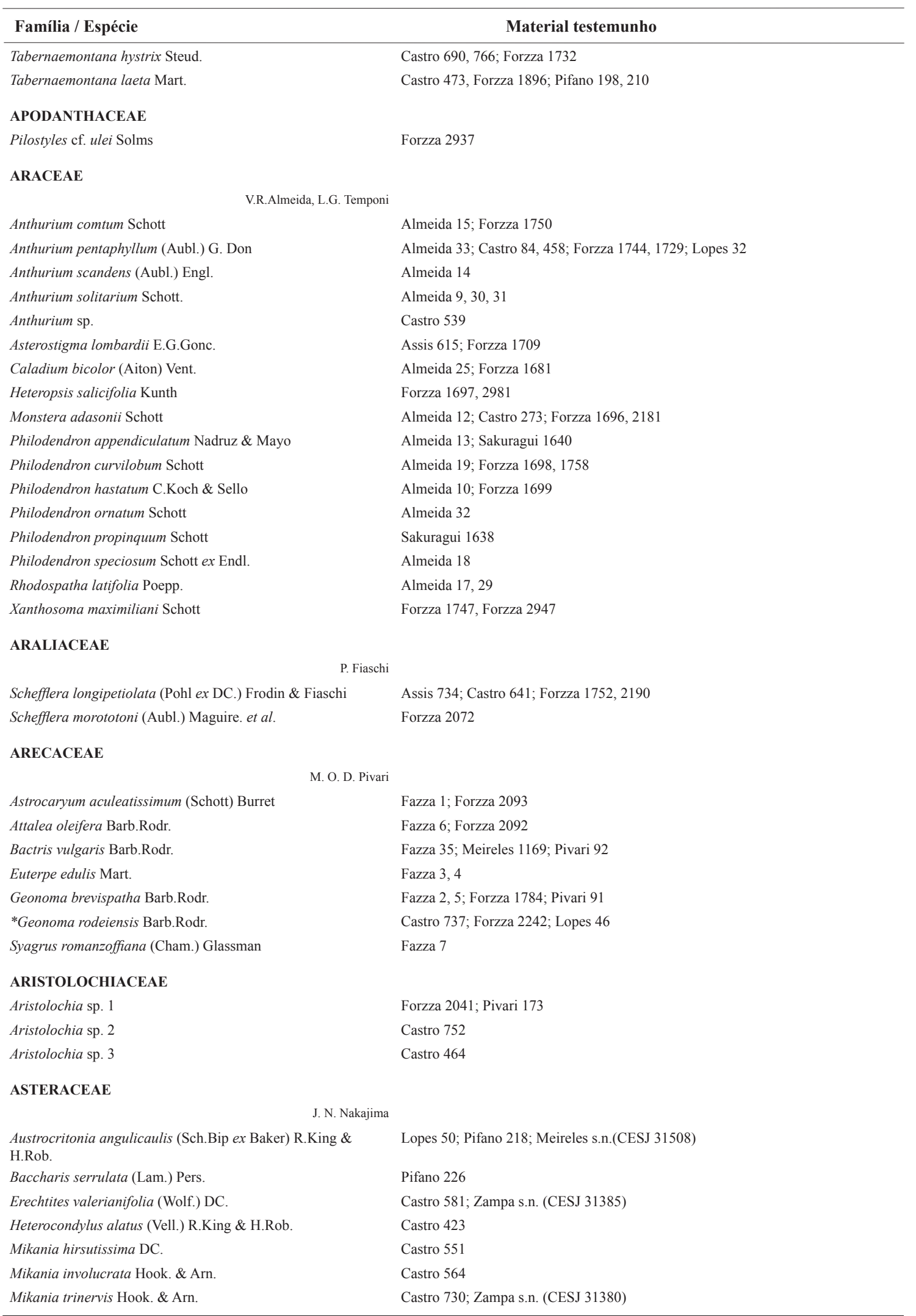


Família / Espécie

Piptocarpha macropoda (DC.) Baker

Vernonanthura phosphorica (Vell.) H.Rob.

\section{BALANOPHORACEAE}

Lophophytum mirabile Schott \& Endl.

\section{BEGONIACEAE}

Begonia angulata Vell.

Begonia fischeri Schrank

Begonia fruticosa (Klotzsch) A.DC.

Begonia hugelii (Klotzsch) A.DC.

\section{BIGNONIACEAE}

*Adenocalymna coriaceum A.DC.

*Adenocalymna salmoneum J.C.Gomes

Amphilophium crucigerum (L.) L.G.Lohmann

Anemopaegma setilobum A.H.Gentry

Arrabidaea sego (Vell.) DC.

Cybistax antisyphilitica (Mart.) Mart.

Dolichandra unguis-cati (L.) L.G.Lohmann

*Fridericia cinerea (Bureau ex K.Schum.) L.G.Lohmann

Fridericia leucopogon (Cham.) L.G.Lohmann

Fridericia pubescens (L.) L.G.Lohmann

Fridericia speciosa Mart.

Fridericia triplinervia (Mart. ex DC.) L.G.Lohmann

Federicia sp.

Handroanthus chrysotrichus (Mart. ex DC.) Mattos

*Handroanthus pulcherrimus (Sandwith) Mattos

Jacaranda puberula Cham.

Lundia corymbifera (Vahl) Sandwith

Mansoa difficilis (Cham.) Bureau \& K.Schum.

*Mansoa glaziovii Bureau \& K. Schum.

Pyrostegia venusta (Ker Gawl.) Miers

Sparattosperma leucanthum (Vell.) K.Schum.

Stizophyllum perforatum (Cham.) Miers

*Tabebuia stenocalyx Sprague \& Stapf

Tanaecium pyramidatum (Rich.) L.G.Lohmann

Tanaecium selloi (Spreng.) L.G.Lohmann

Xylophragma myrianthum (Cham. ex Steud.) Sprague

Zeyheria tuberculosa (Vell.) Bureau ex Verl.

\section{BORAGINACEAE}

Cordia axillaris I. M. Johnst.

Cordia ecalyculata Vell.

Cordia sellowiana Cham.

*Cordia trachyphyla Mart.

Cordia trichotoma (Vell.) Arráb. ex Steud.

Cordia sp.

Tournefortia bicolor $\mathrm{Sw}$.

Tournefortia paniculata Cham.

Varronia guazumaefolia Desv.

Castro 108

$$
\text { J. M. A. Braga }
$$

Meireles s.n. (RB 403133)

\section{Material testemunho}

Castro 496, 578; Forzza 1873; Salimena s.n. (CESJ 31412, 34796)

Castro 462; Forzza 2233; Lopes 27

\section{E. Lima Jacques}

Forzza 2111

Menini Neto 3

Faria s.n. (CESJ 34482)

Castro 593

L. Lohmann

Castro 83, 135, 513; Forzza 2038, 2978; Meireles (CESJ 31493)

Castro 289; 509

Meireles s.n. (CESJ 31491)

Castro 54, 75, 129, 503; Forzza 2047; Pivari 95; Salimena s.n.(CESJ 31164)

Forzza 1760

Castro 277; Forzza 1730, 1768; Salimena 942

Valente 314

Castro 506

Assis 747; Castro 99; Franco 62

Castro 105, 116, 154; Forzza1765, 2083

Castro 440, 480, 544; Pifano 217

Assis 742

Assis 738

Assis 604; Castro 743; Forzza 1897, 2096; Salimena 941

Castro 588

Castro 585, 610; Zampa s.n. (CESJ 31384)

Castro 269, 489; Forzza 2042

Assis 774; Forzza 2204

Castro 577, 604

Castro 524, 576

Castro 79, 587

Castro 572; Forzza 2235

Castro 552, 569; Forzza 1885

Castro 229; Pifano 185

Assis 608

Castro 449; Forzza 2050; Franco 71

E. F. Guimarãe

Castro 687

Forzza 1764, 2097

Forzza 1902

Castro 554

Castro 292, 311

Castro 713

Castro 107; Forzza 1901; Salimena 949

Castro 680; Pifano 187

Castro 570 


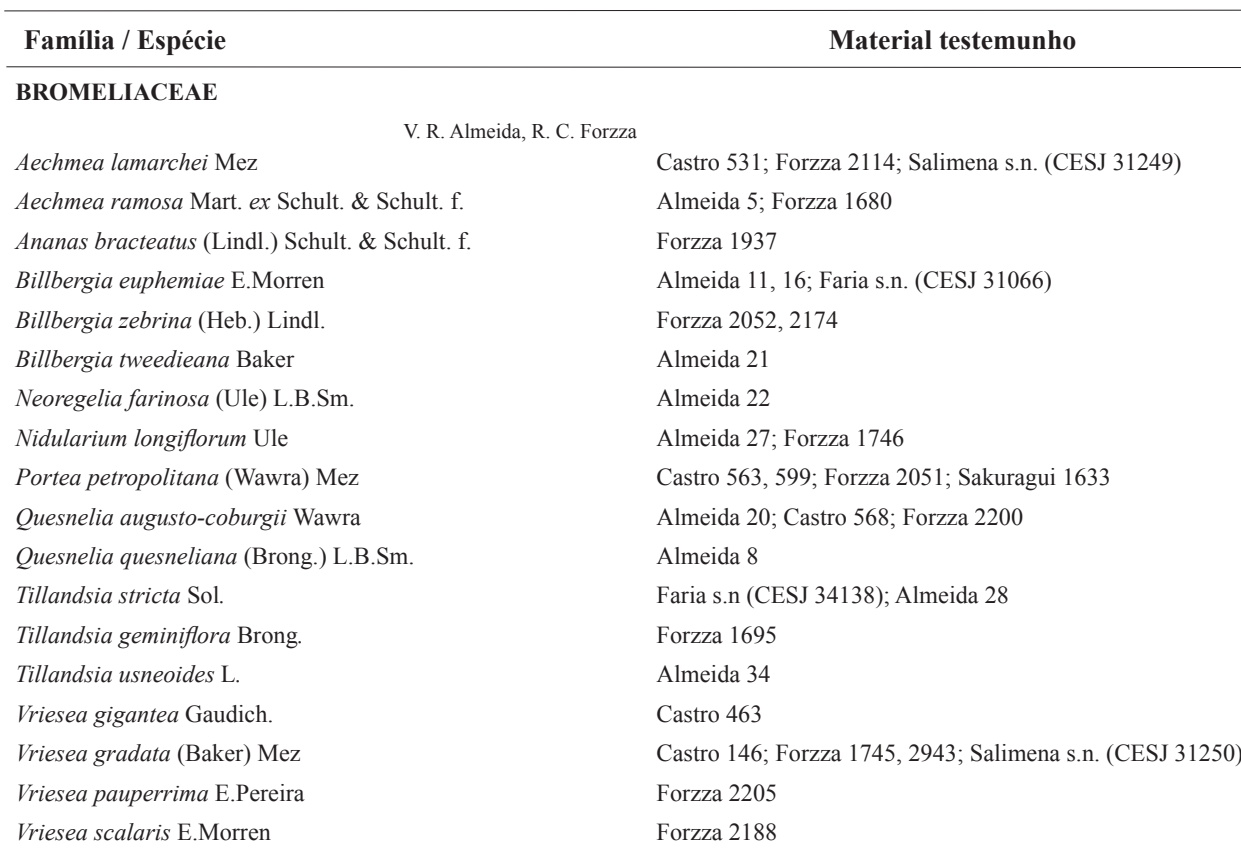

\section{BURSERACEAE}

Protium heptaphyllum (Aubl.) Marchand

*Protium kleinii Cuatrec.

\section{CACTACEAE}

Epiphyllum phyllanthus (L.) Haw.

Hylocereus setaceus (Salm-Dyck) R.Bauer

Lepismium cruciforme (Vell.) Miq.

Pereskia aculeata Mill.

Rhipsalis elliptica G.A.Lindb. ex K.Schum.

Rhipsalis lindbergiana K.Schum.

CAMPANULACEAE

Centropogon cornutus (L.) Druce

Lobelia exaltata Pohl

\section{CANNABACEAE}

Celtis pubescens (Kunth) Spreng

Celtis iguanaea (Jacq.) Sarg.

Trema micrantha (L.) Blume

\section{CARICACEAE}

*Jacaratia spinosa (Aubl.) A.DC.

\section{CARIOCARACEAE}

* Cariocar edule Casar.

\section{CELASTRACEAE}

Cheiloclinium cognatum (Miers.) A.C.Sm.

Hippocratea volubilis $\mathrm{L}$.

Maytenus evonymoides Reissek

*Maytenus communis Reissek

Maytenus salicifolia Reissek
L. R. Lima

Meireles s.n. (CESJ 48655)

Meireles s.n. (CESJ 48656)

D. Zappi

Forzza 2957

Forzza 2044

Forzza 2044

Sakuragui 1636

Forzza 2057

Forzza 2920

Castro 605; Forzza 2976; Valente 313

Castro 113

R. M. Castro

Assis 614; Castro 672

Castro 319; Forzza 1872

Castro 729

Castro 668; Salimena s.n. (CESJ 31407)

Assis 735

J. Lombard

Pifano 347

Castro 573

Salimena 932

Faria s.n. (CESJ 31063)

Castro 77

Rodriguésia 65(2): A1-A19. 2014 
Família / Espécie

Material testemunho

\section{CHRYSOBALANACEAE}

Hirtella hebeclada Moric. ex DC.

*Licania hypoleuca Benth.

Licania octandra (Hoffmanns. ex Roem. \& Schult.) Kuntze

\section{CLUSIACEAE}

*Tovomita bahiensis Engl.

*Tovomita fructipendula (Ruiz \& Pav.) Cambess.

Tovomitopsis paniculata (Spreng) Planch \& Triana

Tovomitopsis saldanhae Engl.

\section{COMBRETACEAE}

Buchenavia cf. tomentosa Eichler

Combretum fruticosum (Loefl.) Stuntz.

Terminalia argentea Mart.

\section{COMMELINACEAE}

Dichorisandra hexandra (Aubl.) Standl.

Dichorisandra pubescens Mart.

Dichorisandra sp. 1

Dichorisandra sp. 2

\section{CONNARACEAE}

Bernardinia fluminensis (Gardner) Planch.

\section{CONVOLVULACEAE}

Ipomea saopaulista O'Donell

Merremia macrocalyx (Ruiz \& Pav.) O'Donell

Odonellia eriocephala (Moric.) K.R.Robertson

\section{COSTACEAE}

Costus spiralis Rosc.

\section{CUCURBITACEAE}

Cayaponia cabocla Cogn.

Cayaponia pilosa (Vell.) Cogn.

Melothria fluminensis Gardner

Melothrianthus smilacifolius (Cogn.) Mart.Crov.

*Wilbrandia ebracteata Cogn.

*Wilbrandia verticillata (Vell.) Cogn.

\section{CUNONIACEAE}

Lamanonia cuneata (Cambess.) Kuntz.

Lamanonia ternata Vell.

\section{CYCLANTHACEAE}

Asplundia brachypus (Drude) Harling

\section{CYPERACEAE}

Cyperus laxus Lam.

Cyperus luzulae (L.) Retz.

Eleocharis debilis Kunth.

Pleurostachys beyrichii (Nees) Steud.

Pleurostachys gaudichaudii Brongn.

Hypolytrum schraderianum Nees
Castro 742; Forzza 1684

Castro 677; Forzza 1880

Castro 670

Forzza 2926

Forzza 2211

Meireles s.n. (CESJ 31484, 31502); Salimena s.n. (CESJ 31009, 31404)

Forzza 1905

N. Marquete

Meireles s.n. (CESJ 48657)

Castro 548

Meireles s.n. (CESJ 48658)

Faria s.n. (CESJ 31101); Forzza 2075; Assis 731; Forzza 2921; Castro 771

Meireles s.n. (CESJ 31486); Castro 86; Forzza 1710; Sakuragui 1635

Forzza 1742

Forzza 2929

Castro 184; Assis 613

R. Bianchini

Castro 98

Castro 414, 266; Lopes 48

Franco 78

Zampa s.n. (CESJ 31073)

Assis 609; Forzza 2071

Castro 317

Castro 425; Faria s.n. (CESJ 31108); Forzza 2970

Forzza 1853, 2105, 2228; Lopes 1, 44

Forzza 2927

Forzza 2972; Franco 70

Castro 749

Castro 479; Salimena s.n. (CESJ 31162)

Forzza 1743, 2946

A. Gil

Castro 731

Forzza 1701

Franco 80

Menini Neto 4

Faria s.n (CESJ 31131); Lopes 12

Faria s.n. (CESJ 31150); Zampa s.n. (CESJ 31081) 


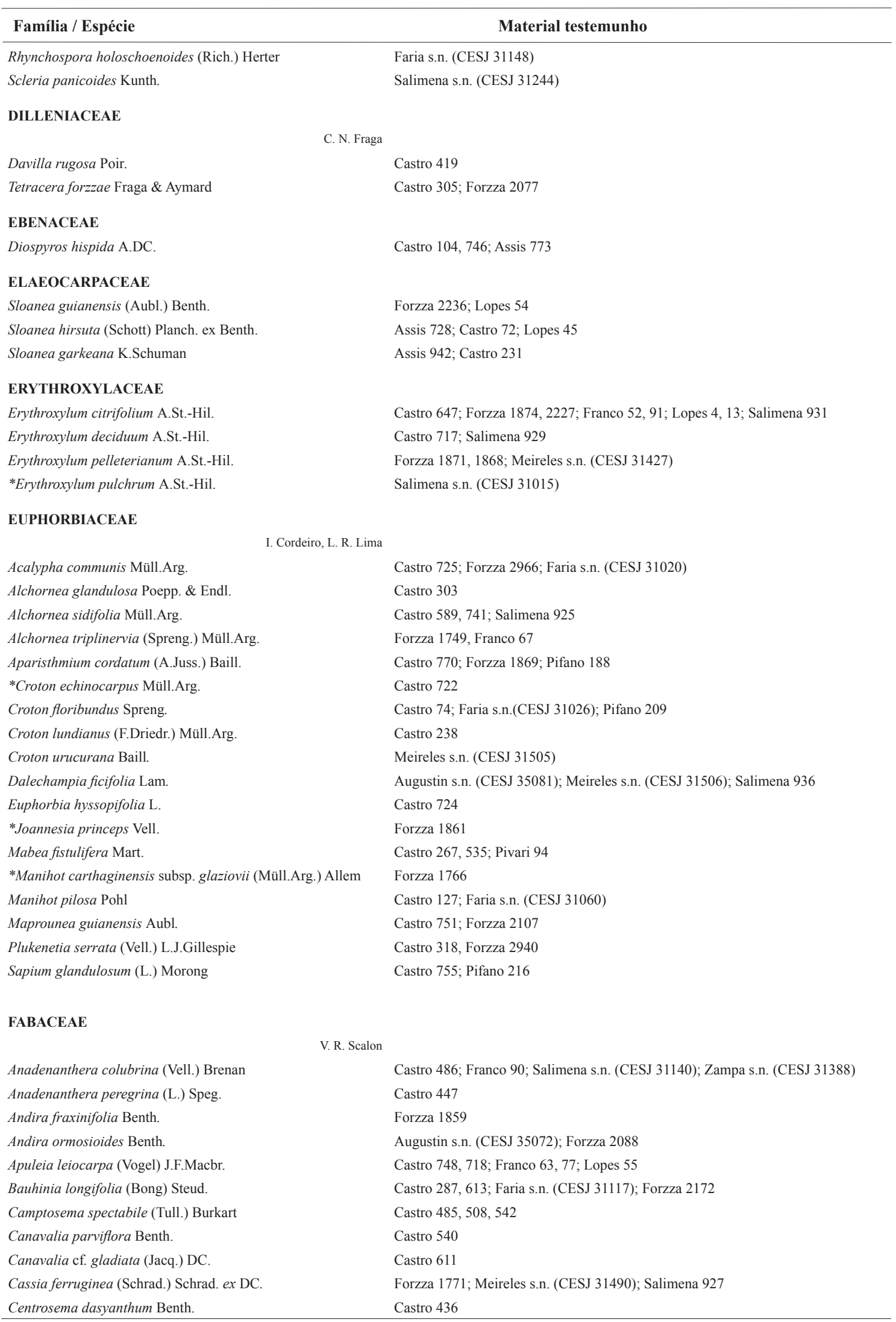




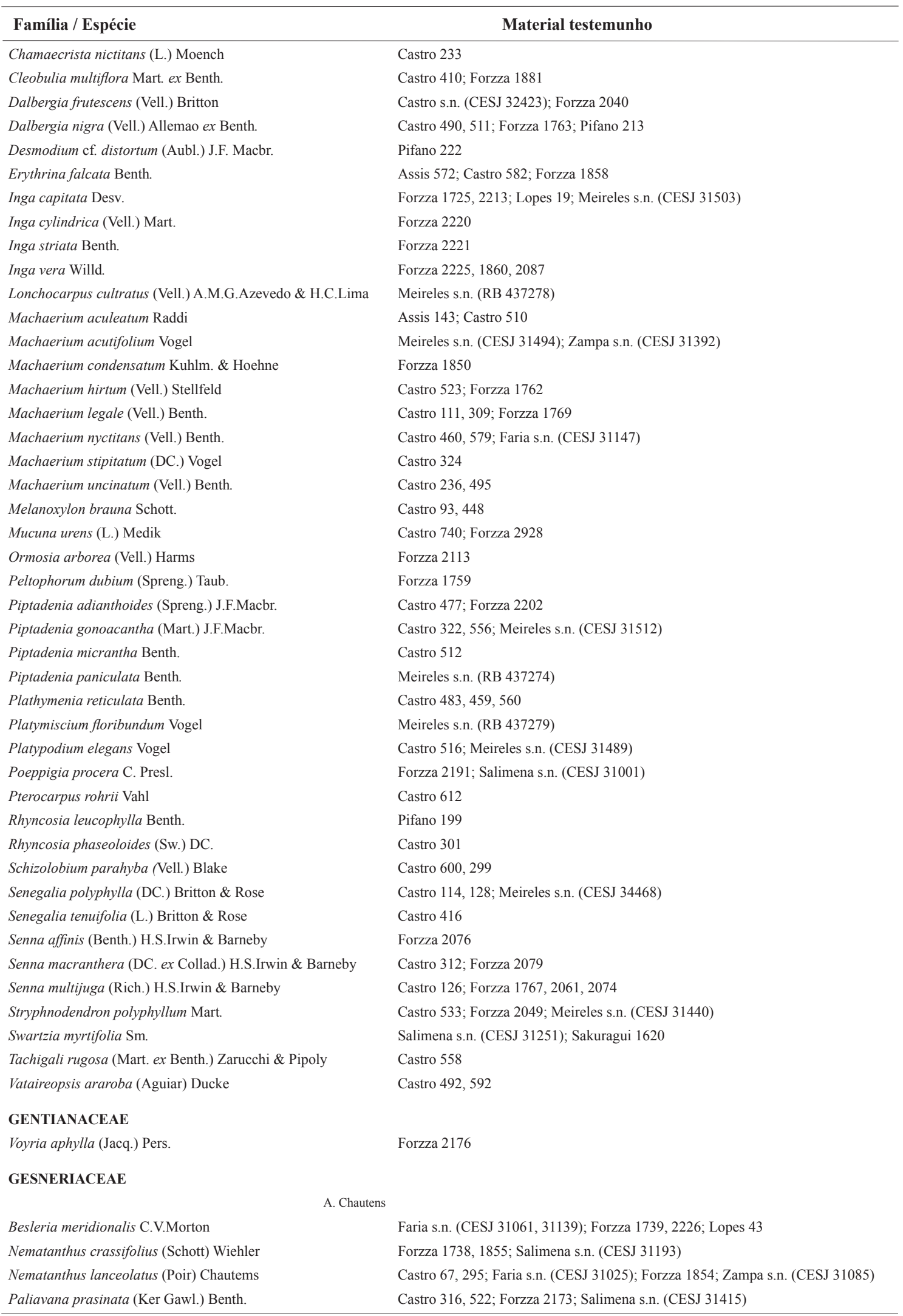




Família / Espécie Material testemunho

\section{HELICONIACEAE}

Heliconia angusta Vell.

Castro 285, 654; Forzza 1719; Menini Neto 6; Mynssen 762

\section{HYPERICACEAE}

Vismia magnoliaefolia Cham. \& Schltdl.

\section{IRIDACEAE}

Neomarica glauca (Seub. ex Klatt) Sprague

\section{LACISTEMATACEAE}

Lacistema pubescens Mart.

\section{LAMIACEAE}

Aegiphila integrifolia (Jacq.) Moldenke

Hyptidendron asperrimum (Spreng.) Harley

Vitex cf. megapotaminca (Spreng.) Moldenke

Vitex polygama Cham.
Castro 695; Pifano 191; Salimena 923

Forzza 1724, 2216, Sakuragui 1622

Castro 437, 530. 571, 609; Forzza 1862; Salimena 930

Forzza 1770; Pifano 205

Castro 601; Forzza 1888

Forzza 2082

Castro 765

\section{LAURACEAE}

L. Assis, H. van der Werff

Aniba firmula (Nees \& Mart.) Mez

Beilschmiedia taubertiana (Schwacke \& Mez) Kosterm.

Cryptocarya micrantha Meisn.

Endlicheria paniculata (Spreng.) J.F.Macbr.

Nectandra megapotamica (Spreng.) Mez

Nectandra membranacea (Sw.) Griseb.

Nectandra oppositifolia Nees

Nectandra psammophila Nees

Ocotea aciphylla (Nees \& Mart.) Mez

Ocotea brachybotrya (Meisn.) Mez

Ocotea corymbosa (Meisn.) Mez

Ocotea divaricata (Nees) Mez

Ocotea sassafras (Meisn.) Mez

Ocotea odorifera (Vell.) Rohwer

Urbanodendron verruculosum (Nees) Mez

\section{LECYTHIDACEAE}

Cariniana estrellensis (Raddi) Kuntze

*Lecythis lanceolata Poir

Lecythis lurida (Meirs) Mori

\section{LORANTHACEAE}

Psittacanthus dichroos (Mart.) Mart.

\section{MALPIGHIACEAE}

Banisteriopsis muricata (Cav.) Cuatrec.

Banisteriopsis sp.

Byrsonima intermedia A.Juss

Carolus chlorocarpus (A.Juss.) W.R.Anderson

Diplopterys pubipetala (A.Juss.) W.R.Anderson \& C.Cav.Davis

Heteropterys intermedia (A.Juss.) Griseb.

Heteropterys lindleyana A.Juss.

Heteropterys sericea (Cav.) A.Juss.

Heteropterys sp.

Hiraea sp.

A. M. Amorim
Assis 602, 800; Castro 720, 738; Faria s.n. (CESJ 41124); Forzza 1878

Assis 856, 880; Lopes 38; Valente 316

Castro 640

Assis 574, 803, 943; Castro 482, 433, 584; Forzza 2039; Franco 59; Pifano 194

Assis 745, 798, 799, 940; Faria s.n. (CESJ 40764)

Assis 475, 736; Castro 152, 517, 580; Forzza 2058, 2089

Assis 739, 804; Castro 280, 674; Forzza 1879, 2046; Pifano 215

Assis 569

Assis 797, 881, 941

Assis 603, 733, 747; Castro 666; Faria s.n. (CESJ 31120); Forzza 2069; Meireles s.n. (CESJ 31419$)$; Salimena s.n. (CESJ 31405); Zampa s.n. (CESJ 31088)
Forzza 1894

Assis 568, 570, 888; Castro 426; Forzza 2106

Assis 573; Forzza 1702, 2931

Assis 571, 737, 882; Castro 481, 596; Faria s.n. (CESJ 31144); Meireles s.n. (CESJ F1423) 2982

Castro s.n. (CESJ 34486); Salimena s.n. (CESJ 31306); Sakuragui 1621

Castro 476, 675; Forzza 2091; Salimena s.n. (CESJ 31248)

Faria s.n. (CESJ 31070)

Franco 65; Pifano 211

Castro 110; Forzza 2078

Castro 232, 277

Castro 73, 682

Faria s.n. (CESJ 31030); Zampa s.n. (CESJ 31383); Salimena s.n. (CESJ 31240)

Forzza 1877

Castro 768; Franco 74; Forzza 2037, 2054

Castro 435

Assis 612; Castro 545, 586

Forzza 1875

Castro 708 


\begin{tabular}{|c|c|}
\hline Família / Espécie & Material testemunho \\
\hline Mascagnia sp. & Forzza 2239 \\
\hline Mezia araujei Nied. & Forzza 1893 \\
\hline Niedenzuella acutifolia (Cav.) W.R.Anderson & Castro 714 \\
\hline Niedenzuella lucida (A.Juss.) W.R.Anderson & Castro 653; Forzza 2214; Pifano 204; Salimena 946 \\
\hline Stigmaphyllon acuminatum A.Juss. & Castro 246, 445 \\
\hline Stigmaphyllon salzmanni A.Juss. & Castro 443; Salimena s.n. (CESJ 31182, 31248) \\
\hline Stigmaphyllon tomentosum A.Juss. & Castro 302 \\
\hline Stigmaphyllon urenifolium A.Juss. & Forzza 1887 \\
\hline Stigmaphyllon sp. & Castro 500 \\
\hline Tetrapterys mucronata Cav. & Castro 597 \\
\hline Tetrapterys phlomoides (Spreng.) Nied. & Forzza 2109 \\
\hline \multicolumn{2}{|l|}{ MALVACEAE } \\
\hline \multicolumn{2}{|c|}{ M. Bovini } \\
\hline Abutilon rufinerve A.St.-Hil. & Castro 555; Forzza 2239 \\
\hline Ceiba speciosa (A.St.-Hil.) Ravenna & Castro 102 \\
\hline Eriotheca candolleana (K.Schum.) A.Robyns & Forzza 2231 \\
\hline Luehea candicans Mart. \& Zucc. & Castro 754 \\
\hline Luehea grandiflora Mart. \& Zucc. & Castro 94, 413, 439 \\
\hline Pseudobombax grandiflorum (Cav.) A.Robyns & Castro 559; Forzza 2206 \\
\hline Sterculia curiosa (Vell.) Taroda & Meireles s.n. (CESJ 33703) \\
\hline Triumfetta semitriloba Jacq. & Castro 117 \\
\hline \multicolumn{2}{|l|}{ MARANTACEAE } \\
\hline \multicolumn{2}{|c|}{ J. M. A. Braga } \\
\hline Calathea monophylla (Vell.) Körn. & Forzza 1720, 1740, 2056 \\
\hline Ctenanthe compressa (A.Dietr.) Eichl. & Forzza 2965 \\
\hline *Ctenanthe lanceolata Petersen & Forzza 1682, 2029, 2924 \\
\hline Stromanthe confusa K.Schum. & Forzza 2108 \\
\hline Stromanthe tonckat (Aubl.) Eichl. & Forzza 2110 \\
\hline \multicolumn{2}{|l|}{ MARCGRAVIACEAE } \\
\hline Marcgravia polyantha Delpino & Meireles 1166 \\
\hline Marcgravia sp. & Franco 64, Pifano 208 \\
\hline \multicolumn{2}{|l|}{ MELASTOMATACEAE } \\
\hline \multicolumn{2}{|l|}{ R. Goldenberg, J. F. Baumgratz, P. J. Guimarães } \\
\hline Pleiochiton blepharodes (DC.) Reginato et al. & Forzza 1721 \\
\hline Clidemia hirta (L.) D.Don & Castro 100, 237; 288; Forzza 2085 \\
\hline Leandra amplexicaulis DC. & Zampa s.n. (CESJ 31083); Salimena s.n. (CEJ 31186) \\
\hline Leandra aptera Cogn. & Pifano 195; Zampa s.n. (CESJ 31041) \\
\hline Leandra bergiana Cogn. & Castro 65 \\
\hline *Leandra dasytricha (A.Gray) Cogn. & Castro 642; Forzza 1690 \\
\hline Leandra nianga Cogn. & Castro 764; Faria s.n. (CESJ 31103); Meireles s.n. (CESJ 31504) \\
\hline Leandra sericea DC. & Castro 699, 704; Faria s.n. (CESJ 31052) \\
\hline Leandra xantholasia (DC.) Cogn. & Salimena 943 \\
\hline Miconia albicans (Sw.) Triana & Assis 611 \\
\hline Miconia budlejoides Triana & Castro 59; Forzza 1687; Salimena s.n. (CESJ 31398) \\
\hline Miconia cinnamomifolia (DC.) Naud. & Castro 709; Forzza 2060 \\
\hline Miconia doriana Cogn. & Castro 407; Forzza 2066; Lopes 5 \\
\hline Miconia latecrenata (DC.) Naudin & Castro 271, 412; Forzza 2208; Lopes 29 \\
\hline Miconia mellina DC. & Castro 95; Forzza 2209 \\
\hline Miconia mendoncae Cogn. & Castro 700 \\
\hline Miconia petropolitana Cogn. & Castro 133; Salimena s.n. (CESJ 31409) \\
\hline Miconia pusilliflora (DC.) Naud. & Castro 60, 136; Faria s.n. (CESJ 31124); Salimena s.n. (CESJ 31016 \\
\hline
\end{tabular}




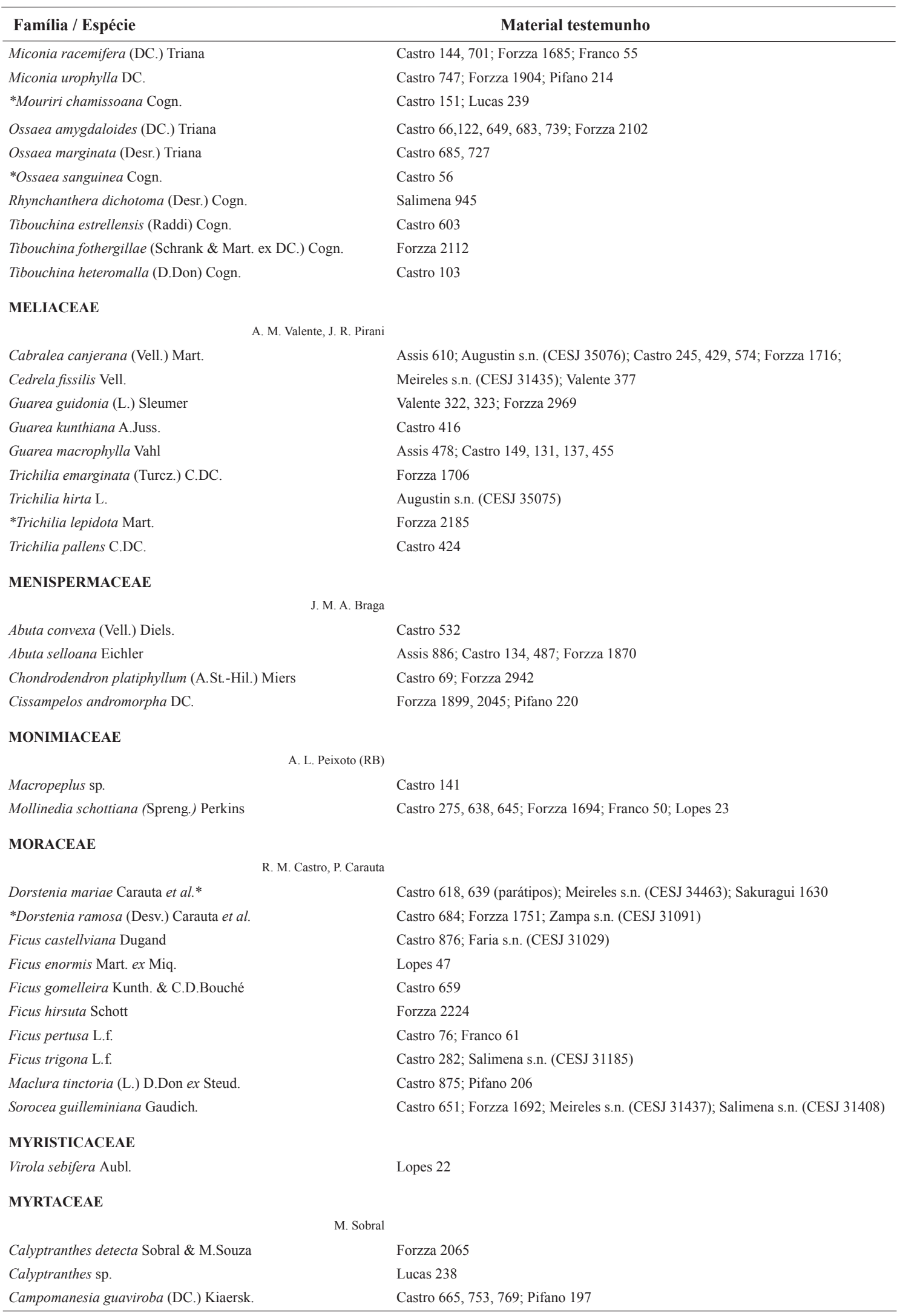




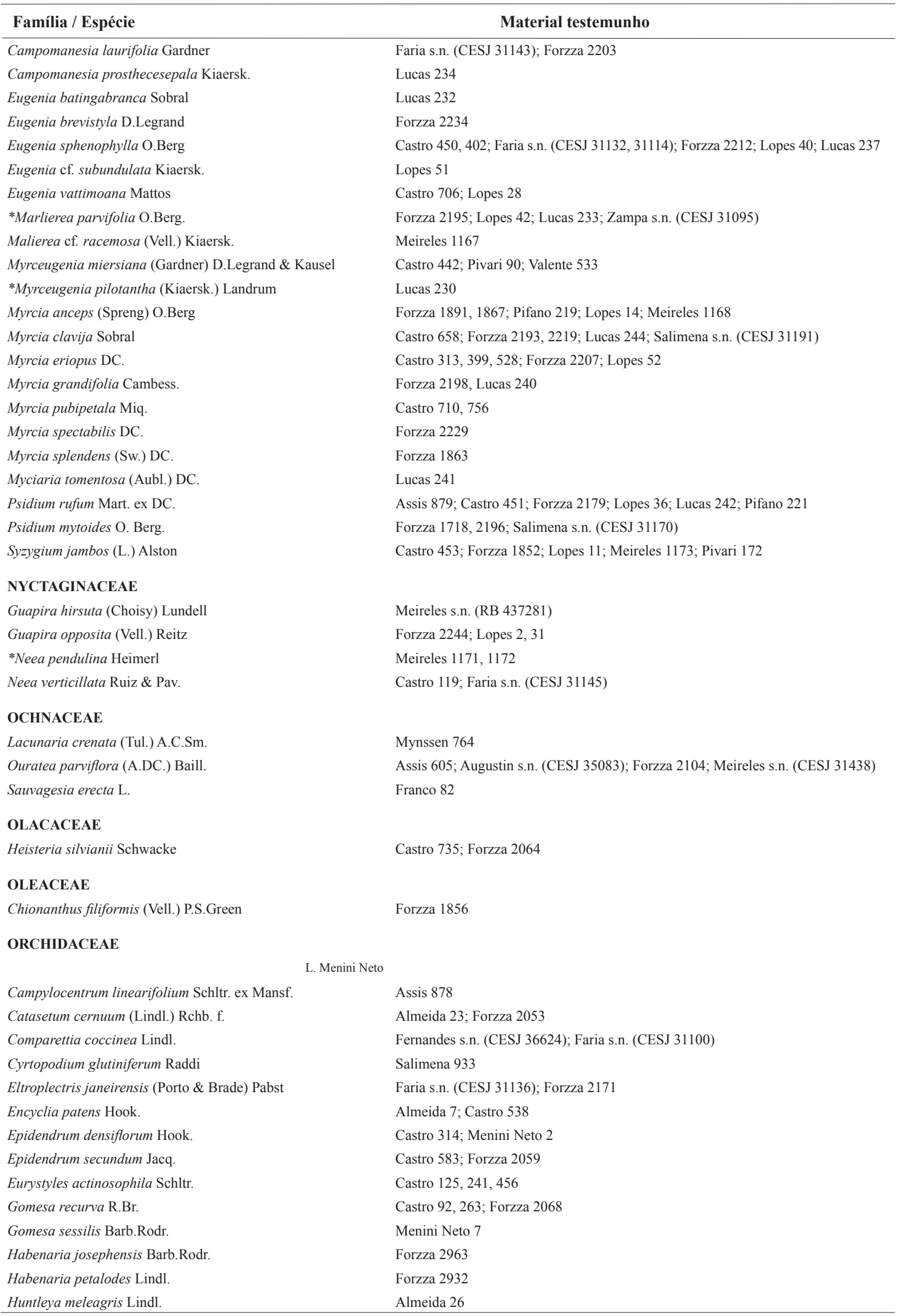




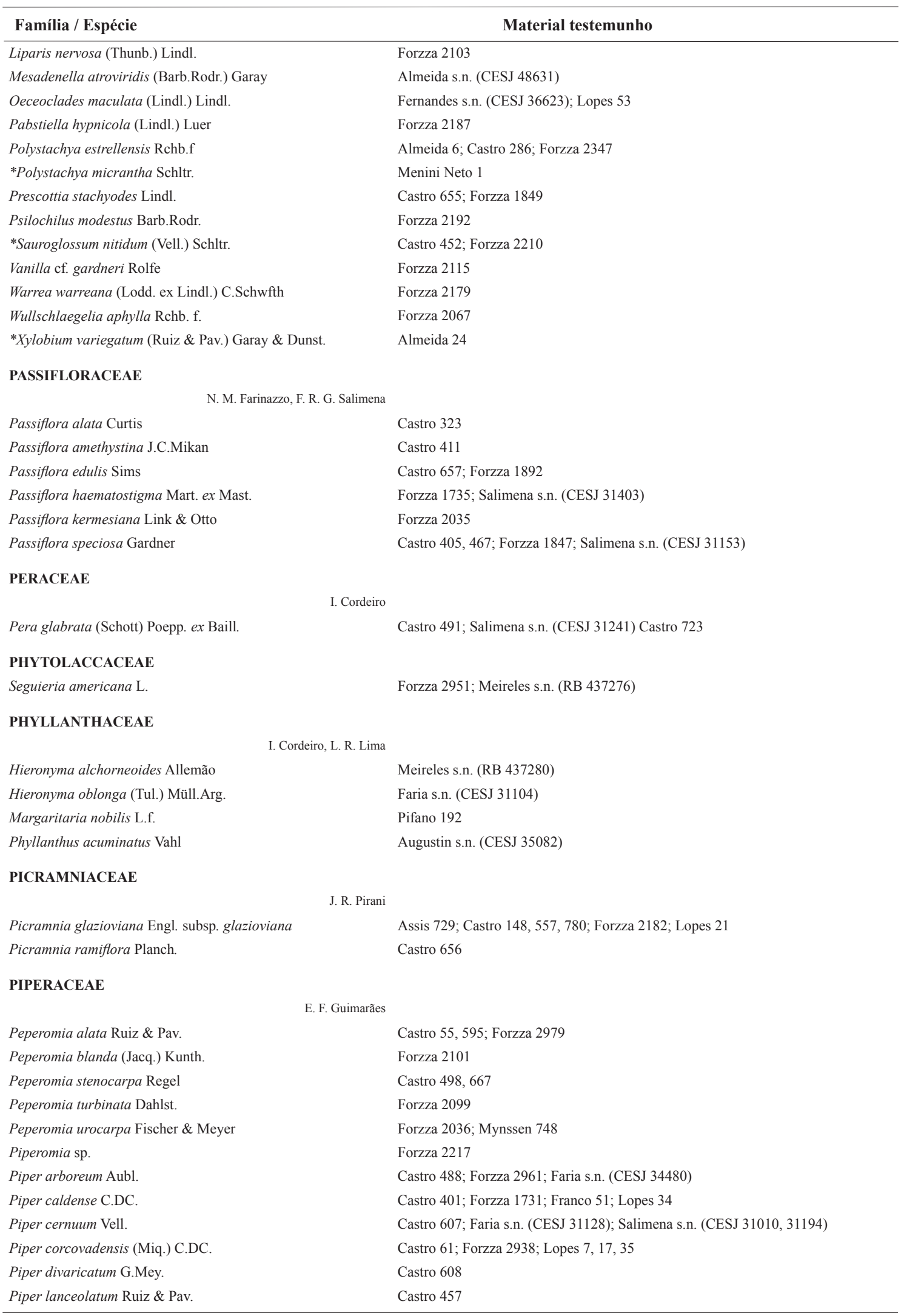




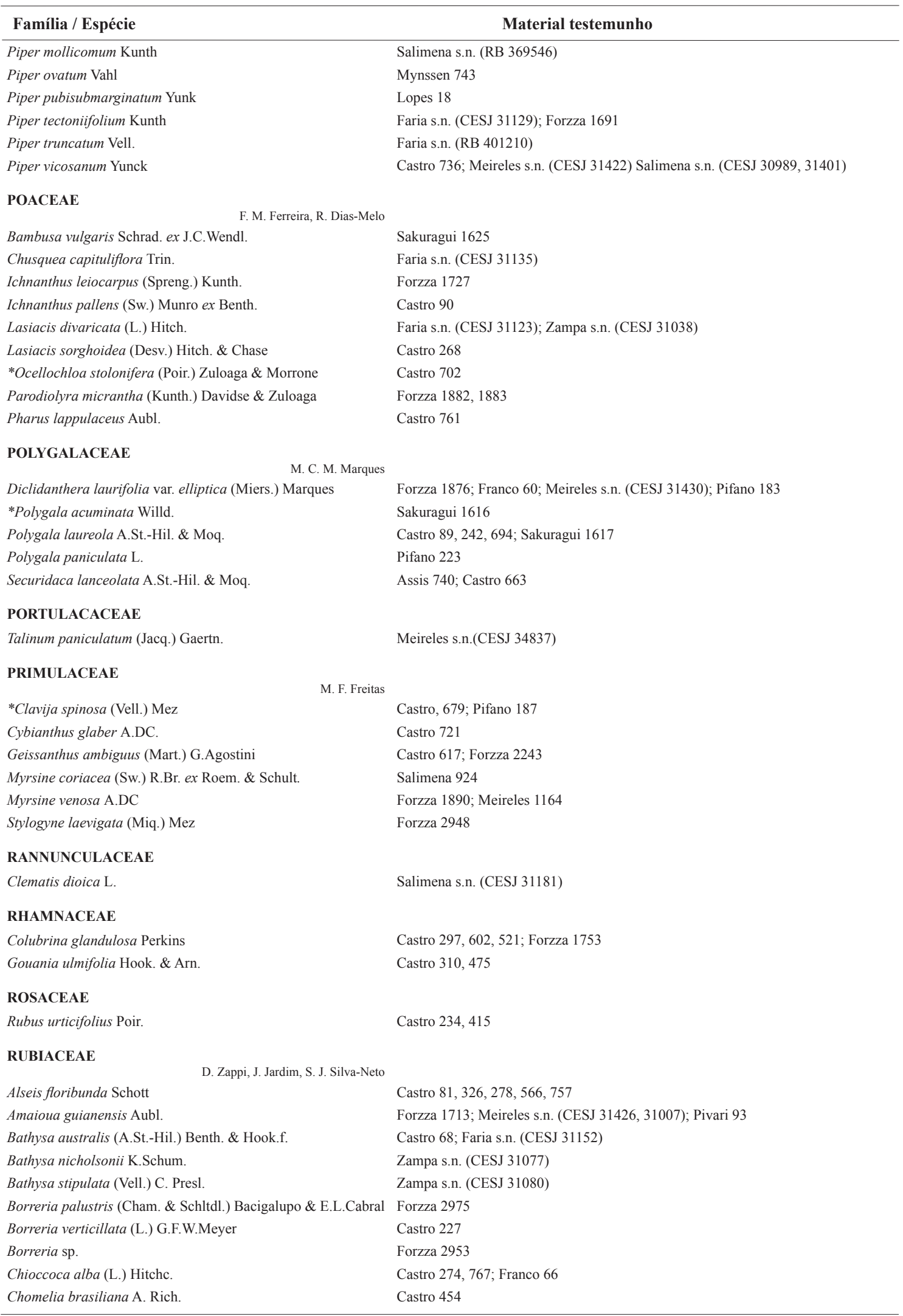




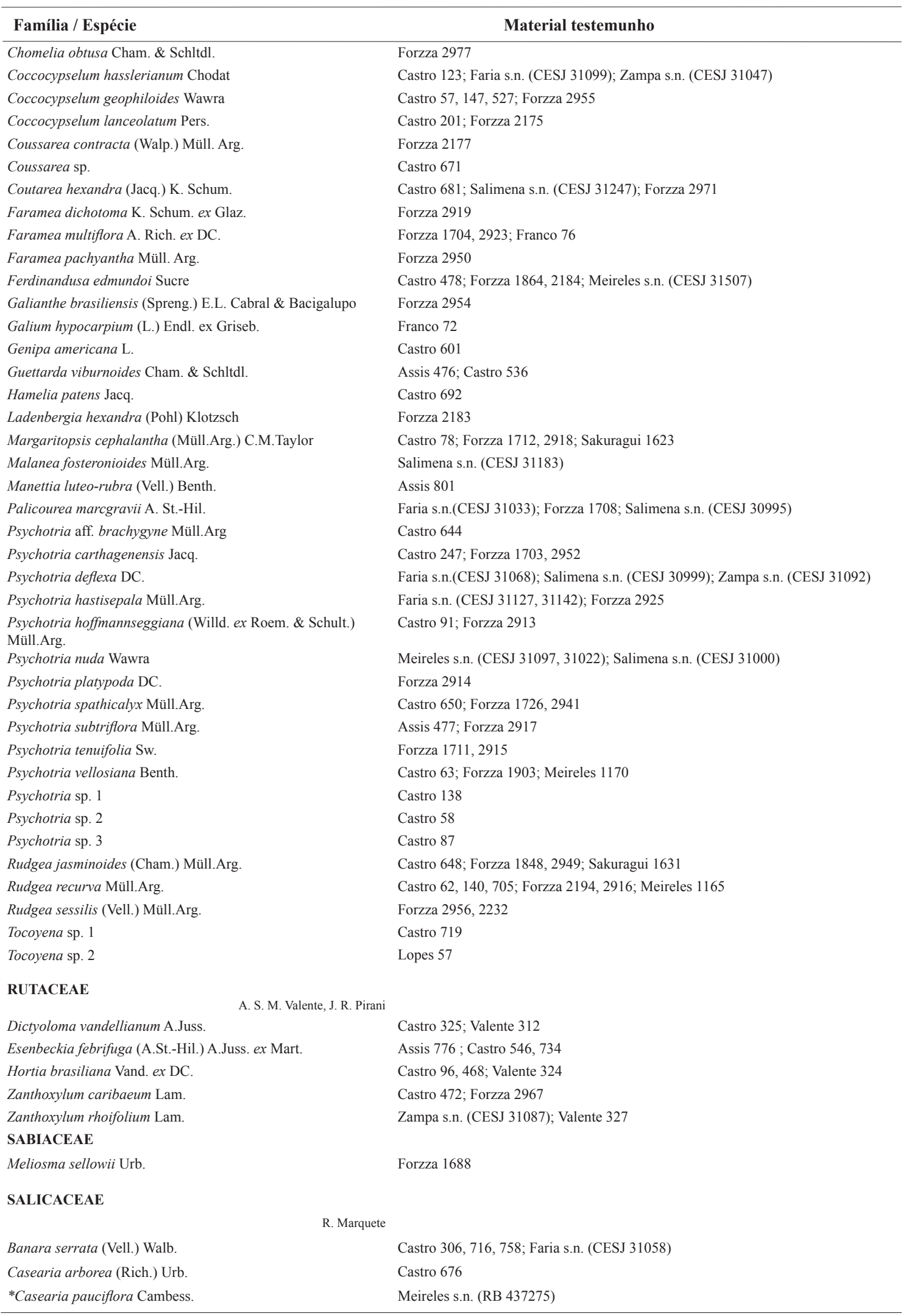




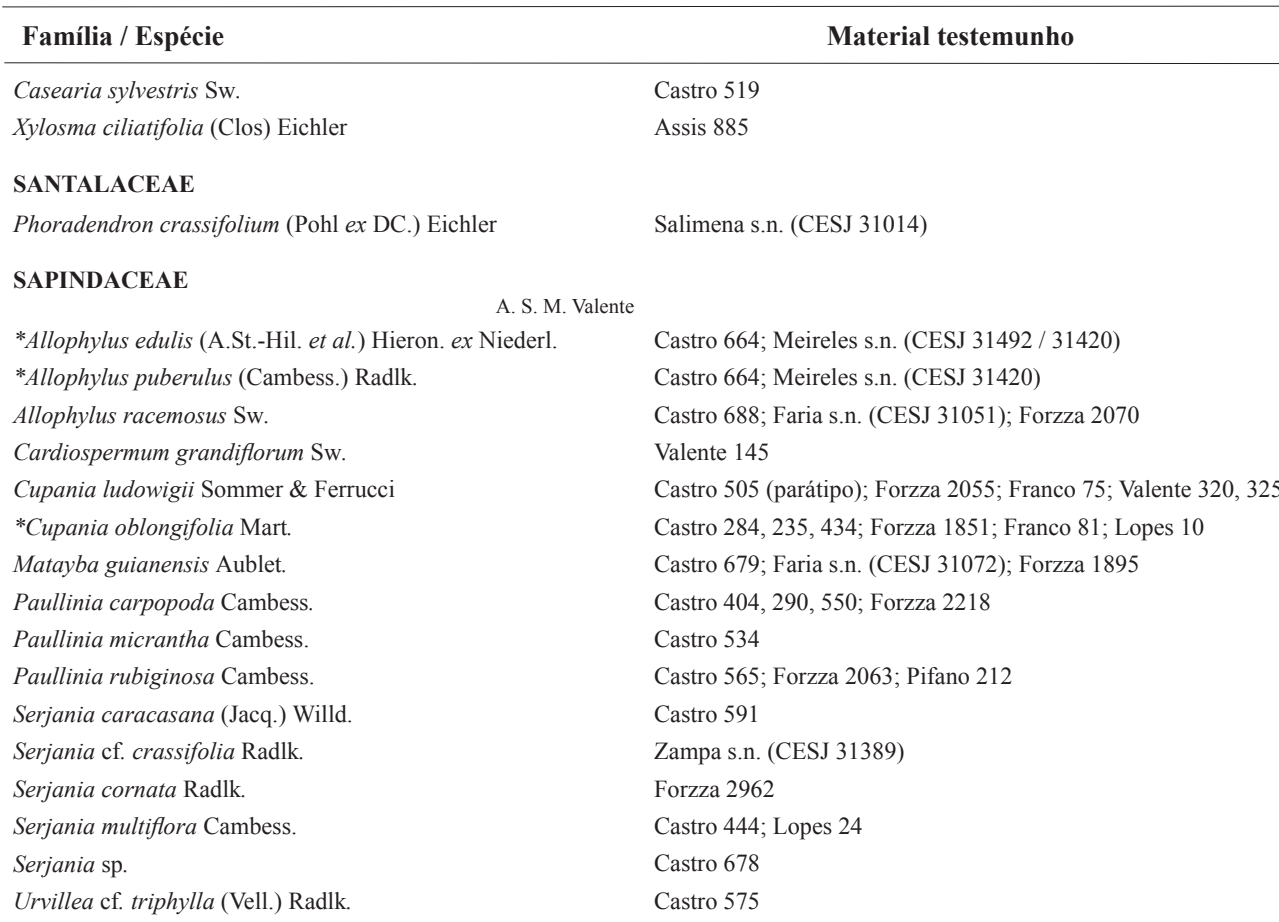

\section{SAPOTACEAE}

Chrysophyllum flexuosum Mart.

Chrysophyllum sp.

Ecclinusa ramiflora Mart.

*Pouteria guianensis Aubl.

*Pradosia lactescens (Vell.) Radlk.

\section{SIPARUNACEAE}

Siparuna brasiliensis (Spreng.) A.DC.

Siparuna guianensis Aubl.

\section{SMILACACEAE}

Smilax quinquenervia Vell.

Smilax stenophylla A.DC.

Smilax syphilitica Humb. \& Bonpl. ex Willd.

\section{SOLANACEAE}

Aureliana fasciculata var. tomentella (Sendtn.) Barboza \&

Huntz.

Brunfelsia hydrangeiformes (Pohl) Benth.

Brunfelsia uniflora (Pohl) D.Don

Cestrum bracteatum Link \& Otto

Cestrum montanum Miers

Cestrum pedicellatum Sendtn.

Dyssochroma viridiflora (Sims) Miers

Solanum asterophorum Mart.

Solanum cernuum Vell.

Solanum decompositiflorum Sendtn.

Solanum gnaphalocarpon Vell.

Solanum granulosoleprosum Dunal

Solanum graveolens Bunbury

Solanum hoehnei C.V.Morton
T. D. Pennington

Assis 474; Castro 239, 762

Castro 526

Forzza 2223

Castro 124; Forzza 2240; Meireles s.n. (CESJ 31442); Salimena s.n. (CESJ 31174)

Faria s.n. (CESJ 31064); Valente 315

A. L. Peixoto

Castro 733

Castro 64; Franco 57; Lopes 15; Salimena 926

R. Andreat

Castro 698; Salimena s.n. (CESJ 31190)

Forzza 2090

Castro 438

Castro 696, 715; Forzza 1686

Castro 643, 139; Forzza 1715; Pifano 189

Castro 82, 120

Castro 150; Meireles s.n. (CESJ 34466); Salimena s.n. (CESJ 31163)

Pifano 321

Castro 529; Forzza 2230; Lopes 58; Salimena 947

Castro 494, 240; Forzza 2958

Castro 466

Assis 946; Salimena 948

Castro 446, 264

Meireles s.n. (CESJ 31510)

Assis 948; Castro 525 304; Salimena 935

Castro 693

Sakuragui 1628 


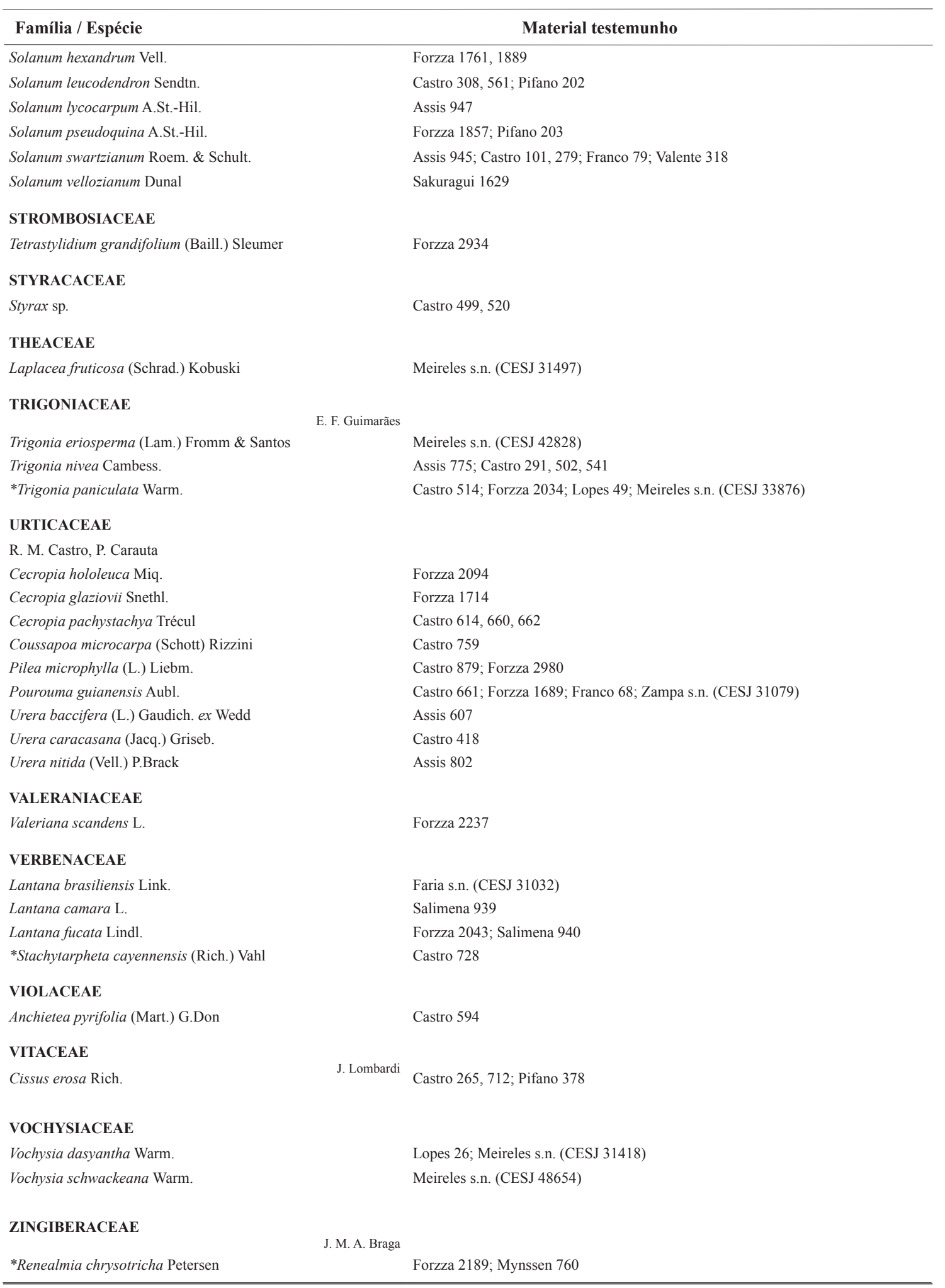

